Cheng, B., Wang, M., Yang, S.J.H., Kinshuk, Peng, J. (2011). Acceptance of competency-based workplace e-learning systems: effects of individual and peer learning support. Computers \& Education, 57(1), 1317-1333.

\title{
Acceptance of Competency-Based Workplace E-Learning Systems: Effects of Individual and Peer Learning Support
}

\author{
Bo Cheng ${ }^{a}$, Minhong Wang ${ }^{a}$, Stephen J.H. Yang ${ }^{b}$, Kinshuk ${ }^{c}$, Jun Peng ${ }^{a}$ \\ ${ }^{a}$ Faculty of Education, The University of Hong Kong \\ ${ }^{\mathrm{b}}$ Department of Computer Science and Information Engineering, National Central University \\ ${ }^{\mathrm{c}}$ Athabasca University \\ Corresponding author: Minhong Wang (magwang@hku.hk)
}

\begin{abstract}
Current endeavors to integrate competency-based learning approaches with e-learning systems design for delivery of training to adult learners in the workplace are growing. However, academic efforts in examining learners' perceptions of, and reactions towards, this technology-delivered pedagogical innovation are limited. Drawing together perspectives from the literature on training and instructional design and technology acceptance, this research proposed a conceptual model to examine the influences of perceived individual and social learning support on employees' acceptance of competency-based e-learning systems. Structural equation modeling and multi-group structural equation modeling techniques were applied to sample data collected from work settings in mainland China. The results show the positive effects of perceived individual learning support and perceived support for promoting a norm of cooperation on employees' intention to use the competency-based e-learning system. It was also found that perceived support for enhancing social ties had a negative effect on employees' behavioral intention. The gender, age, and prior experience differences in the main effects were also investigated.
\end{abstract}

\section{KEYWORDS}

Adult Learning; Evaluation of CAL systems; Pedagogical issues; Distance education and telelearning; Cooperative/collaborative learning.

\section{INTRODUCTION}

E-learning is increasingly being used by organizations as an emergent approach for enhancing the skills of knowledge workers. In the training and human resource development (HRD) literature, e-learning is regarded as a training "medium" (Salas, Kosarzycki, Burke, Fiore \& Stone, 2002; Tynjälä \& Häkkinen, 2005), "instructional strategy" (Burgess \& Russell, 2003; DeRouin, Fritzsche \& Salas, 2004; Klein, Noe \& Wang, 2006), or learning "environment" (DeRouin, Fritzsche, Salas \& Martocchio, 2004; Tynjälä \& Häkkinen, 2005) for delivery of training to employees using computer ad web-based technologies. As a "killer application" for employee training and workforce development (Henry, 2001; DeRouin, Fritzsche \& Salas, 2004), 
e-learning offers the benefits of cost-effectiveness, delivery-efficiency, self-management of learning, on-demand training, and time/place-free availability (Welsh, Wanberg, Brown \& Simmering, 2003; Salas, Kosarzycki, Burke, Fiore \& Stone, 2002; Murray, 2001). It also accounts for a significant proportion of corporate investment in training (Salas, Kosarzycki, Burke, Fiore \& Stone, 2002; SkillSoft, 2010; Little, 2010; Patterson, Jung \& Broadhead, 2009).

While e-learning is increasingly being adopted as a training approach in HRD practices (Burgess \& Russell, 2003), the issue of e-learning effectiveness has arisen both in practice and in academia (Park \& Wentling, 2007). The ultimate purpose of work-integrated learning is to drive business results and to bring about positive changes in workplace behaviors and job performance (Bersin, 2002; Park \& Wentling, 2007). However, according to evidence from practices reported in the corporate e-learning literature (e.g., Netteland, Wasson \& Mørch, 2007; Majchrzak, Rice, Malhotra, King \& Ba, 2000), there is a lack of relevance of e-learning programs for employees' work activity and previous experiences. Misalignment has been found to exist between organizational environment and technology-supported learning activities such as knowledge capture and sharing in the workplace. Similarly, "lack of job analysis" and "weak focus on business and performance requirements" have been identified as key barriers to the successful implementation of workplace e-learning (Clark \& Mayer, 2008; Rosenberg, 2006). These barriers may lead to reduced employees' motivation and learning and transfer effectiveness. As a result, alignment of e-learning with job competencies and performance requirements has been recognized as a critical success factor in workplace e-learning effectiveness (Wang, 2010), which elicits the need and lays the empirical foundation for competency-based approaches to be integrated into e-learning development.

In the vocational education and training (VET) literature, competency-based training can be referred to as "competency movement" (Burgoyne, 1993; Rubin, Bebeau, Leigh, Lichtenberg, Nelson, Portnoy, Smith \& Kaslow, 2007), whereby learning is driven by development of specific competencies for dealing with needs and challenges (Ricciardi, 2005). A competency is a combination of skills, abilities, and knowledge needed to perform a specific task. Competency-based training has been widely used by organizations to drive workplace learning initiatives to enable employees to respond quickly and flexibly to business needs. Such practices can be found in management education (Camuffo \& Gerli, 2004), medical education (Long, 2000; Folberg, Antonioli \& Alexander, 2002), and other professional training and education programs (Chang, 2006). In recent years, researchers have made attempts to integrate competency-based models into e-learning programs to allow employees to develop competencies with a broad degree of self-regulation and self-control (Sicilia \& Naeve, 2007). Leyking, Chikova \& Loos (2007) present an approach for aligning a competency-driven learning process with business process contexts via e-learning technology. Wang, Ran, Liao \& Yang (2010) propose the use of Key Performance Indicators (KPIs) as a framework to link learning with work competencies and 
performance in e-learning applications. Schmidt (2008) applies the ontology-based work context and competency modeling approach to support the development of context-aware workplace e-learning. While current endeavors to integrate competency-based approaches to workplace e-learning development are increasing, research that examines employees' perceptions of, and reactions towards, this technology-delivered pedagogical innovation is minimum. Lack of consideration for learners' perceptions and attitudes towards workplace e-learning has been recognized as the key barrier to successful design and implementation of e-learning initiatives (e.g. Servage, 2005; Admiraal \& Lockhorst, 2009; Vaughan \& MacVicar, 2004; Brown, Murphy \& Wade, 2006; Rabak \& Cleveland-Innes, 2006).

The literature on e-learning design suggests that learner control of learning and customization of learning experiences will meet learners' needs and preferences and improve learners' satisfaction and motivation towards e-learning (Clark \& Mayer, 2008; DeRouin, Fritzsche, Salas \& Martocchio, 2004). It is also assumed that learner collaboration in distance learning environments may address learners' social needs and therefore contribute to their satisfaction and motivation towards using online learning (Salas, Kosarzycki, Burke, Fiore \& Stone, 2002). A number of studies have examined the effects of perceived effectiveness of e-learning systems, in terms of individual and social learning support, on the adoption of e-learning in institutional environments (Liu, Chen, Sun, Wible, \& Kuo, 2010; Cho, Cheng, \& Lai, 2009; Pituch, $\&$ Lee, 2006). However, research exploring the potential impact of individual and peer collaborative learning support on the adoption of e-learning in the workplace situation is very limited, much less on the adoption of competency-based e-learning.

With respect to competency-based e-learning in the workplace, it is recognized that supporting a personalized learning process and facilitating peer communication and collaboration are two key elements in the instructional design of such type of learning system (Schmidt, 2008; Woelk \& Lefrere, 2002; Chang, 2006). However, evaluation of the effects of the two elements on learners' perceptions and reactions has been neglected. This study aims to examine instructional design factors that may influence learners' acceptance of competency-based e-learning systems with a focus on the effects of individual and peer learning support. The investigation is based on relevant training and instructional design theories, and validated models that explain information system usage behavior in work settings, such as the Technology Acceptance Model (TAM) and the Unified Theory of Acceptance and Use of Technology (UTAUT).

\section{THEORETICAL BACKGROUND AND RESEARCH HYPOTHESES}

\subsection{Acceptance of Technology and Individual Differences}

To explain user acceptance of new technology, a variety of models consisting of different sets of predictive factors have been produced (Venkatesh, Morris, Davis \& Davis, 2003). Among these, the technology acceptance model (TAM) by Davis (1989) 
is one of the most influential and widely used (King \& He, 2006). TAM posits that users' perceived usefulness and perceived ease of use of a system have positive impacts on their behavioral intention to use the system, and this behavioral intention in turn predicts users' actual usage behavior. By reviewing and empirically comparing the existing user acceptance models, Venkatesh, Morris, Davis \& Davis (2003) formulated and empirically validated a unified theory of acceptance and use of technology (UTAUT). The UTAUT model synthesizes the constructs from eight widely employed models: the theory of reasoned action (TRA), the technology acceptance model (TAM), the motivational model (MM), the theory of planned behavior (TPB), a model combining the technology acceptance model and the theory of planned behavior (combined TAM and TPB), the model of PC utilization (MPCU), the innovation diffusion theory (IDT), and the social cognitive theory (SCT). It also posits four combined constructs as predictors of technology acceptance intention and use behavior: performance expectancy, effort expectancy, social influence, and facilitating conditions; and four individual characteristics variables as moderators between the causal relationships: gender, age, experience, and voluntariness of use.

In the e-learning literature, TAM and UTAUT have been widely employed by researchers to investigate students' intention to use, and continued use of, e-learning systems (e.g. Chiu, Sun, Sun \& Ju, 2007; Limayem \& Cheung, 2008; Chiu \& Wang, 2008; Hayashi, Chen, Ryan \&Wu, 2004; Wang, Wu \& Wang, 2009; Lau \& Woods, 2008; Wang \& Wang, 2008). In contrast to the proliferation of research on the adoption of e-learning by students in institutional contexts, theory-driven empirical studies on the adoption of e-learning in workplace settings are relatively rare. Given the explanatory power of TAM and UTAUT in explaining the behavioral intention to adopt new technologies in diverse situations (King \& He, 2006; Sun \& Zhang, 2006), the two models are adopted as the main framework of this study, with some adjustment to the constructs according to the workplace context.

\subsection{Training and Instructional Design}

Rooted in industrial and organizational psychology, training theory is a field of inquiry concerning workplace learning and development, or specifically, concerning issues of knowledge and skills acquisition, retention, and transfer, as well as the factors that have an impact on these training outcomes (Fleishman, 1997). In training research, workplace learning is viewed as a continuous process relevant to training, socialization, and employee development within an organizational context (Ford, Kozlowski, Kraiger, Salas \& Teachout, 1997). To examine factors influencing workplace learning engagement and effectiveness, researchers have proposed various models (Colquitt, LePine \& Noe, 2000; Burke \& Hutchins, 2007). In these models, individual factors such as needs, attitudes, and goal orientation, and organizational factors such as organizational climate and business strategy are usually identified as antecedents of employees' motivation to participate in workplace learning and learning outcome (Mathieu \& Martineau, 1997; Noe, Wilk, Mullen \& Wanek, 1997). 
In e-learning and distance learning environments, instructional design factors such as providing learner control have been found to have a significant impact on adult learners' reaction towards computer-based instruction (DeRouin, Fritzsche, Salas \& Martocchio, 2004). The theoretical foundation of such investigation can be found in andragogy and self-directed learning theories, which form the basis for the design of e-learning practices in work environments. The implications of adult learning theory for the workplace context are that learners will be motivated once learning objectives have been rationally set that meet their needs, and learning programs should be designed to give emphasis to self-directed learning so as to help learners select and carry out their own learning goals, objectives, methods and means (Merriam, 2001). With e-learning methods, learning can take place on-demand, and learners are given greater control over their learning content, sequence and pace than before. To achieve this, it has been suggested that complex learning content should be segmented into smaller parts, with course maps to define and visualize learning topics and their interrelationships. It has also been suggested that some form of adaptive control be designed that tailors learning to individual needs and motivation in e-learning applications (Clark \& Mayer, 2008).

Moreover, learning is a phenomenon that is situated in a culture and social context. Researchers suggest that learner communication and peer relationship development in a distance learning environment may have an impact on learners' motivation to use online learning in the workplace (Salas, Kosarzycki, Burke, Fiore \& Stone, 2002; Alavi, 1994). The theoretical foundations of such investigation can be found in multiple disciplines such as Communities of Practice (CoPs) and Knowledge Management (KM). A CoP is a group of practitioners with a common interest or purpose, dedicated to supporting each other in increasing their knowledge, creating new insights, and enhancing performance in a particular domain. The assumption of a $\mathrm{CoP}$ is that engagement in social practice is the fundamental process by which people learn and become who they are (Wenger, 2000). KM, from another point of view, refers to a range of approaches and practices used by organizations to identify, create, represent, and distribute knowledge for reuse, awareness, and learning (Nonaka \& Takeuchi, 1995). It focuses on creating opportunities for collaboration between individuals and teams so that intellectual assets can be shared. Crucial to the collaborative learning process is the interaction between novices and experts. Technology offers means of facilitating communication and collaboration, managing knowledge repositories, and increasing access to experts and expertise (Rosenberg, 2006).

The literature discussed above provides useful perspectives and a basis for examining the position of self-regulated individual learning support as well as communication-based social learning support in design of workplace e-learning systems. This theoretical basis and empirical support provided the foundation for developing the conceptual framework of this study. In competency-based learning applications, competencies provide a meaningful conceptual foundation for 
supporting individual learning process based on competency-based course structure and navigational tools that help learners move expeditiously towards their goals. Also, social interactions and knowledge sharing among peer learners can be driven towards the common goal to improve competencies, with the accumulated expertise and experts well recognized and managed around the competencies.

\subsection{Research Model and Hypotheses Development}

Based on the aforesaid gap in the current literature on competency-based workplace E-learning, that is, while great efforts are put into design and implementation issues, little attention is paid to learners' perceptions and reactions, this research proposed a conceptual model as presented in Figure 1, and a set of research hypotheses to be rationalized as the following.

\subsubsection{Perceived Individual Learning Support}

Previous research on the adoption of e-learning following the TAM has indicated that perceived usefulness of e-learning systems in supporting individual learning, such as improving learning performance and learning outcome, has a significant impact on students' use and continuance intention (Cho, Cheng \& Lai, 2009; van Raaij \& Schepers, 2008; Lee, Yoon \& Lee, 2009; Liu, Chen, Sun, Wible \& Kuo, 2010; Lee, 2010; Ngai, Poon \& Chan, 2007). Evidence from research on acceptance of e-learning in the workplace environment also suggests that perceived usefulness of e-learning in improving individual learning effectiveness has a significant effect on employees' attitudes, satisfaction, and use intention towards e-learning (Chen, Yang, Tang, Huang \& Yu, 2007; Hashim, 2008; Roca \& Gagne, 2008; Yeung \& Jordan, 2006; Ong, Lai \& Wang, 2004). Previous research has also found mixed results of gender and age differences in perceptions and acceptance of e-learning technology such as online games and mobile learning (Wang, Wu \& Wang, 2009; Wang \& Wang, 2008; Bonanno \& Kommers, 2008; Lu \& Chiou, 2010). In the information systems literature, research findings suggest that the effect of perceived usefulness on behavior intention is more salient for men than for women (Venkatesh \& Morris, 2000; Sun \& Zhang, 2006; Venkatesh, Morris, Davis \& Davis, 2003), and more salient for younger people than for old people (Sun \& Zhang, 2006; Venkatesh, Morris, Davis \& Davis, 2003). Regarding the moderating effect of prior experience on the relationship between perceived usefulness and intention to use, Taylor \& Todd (1995) hypothesized a stronger influence of perceived usefulness on behavior intention for experienced users, but their findings were to the contrary, which indicated that perceived usefulness was a stronger predictor of behavior intention for inexperienced users. In the e-learning literature, findings from research indicate that after participating in a technology-mediated class, participants have more positive attitudes, satisfaction and use intention towards technology-mediated learning (Welsh, Wanberg, Brown \& Simmering, 2003; Johnson, Lohman, Sharp \& Krenz, 2000).

Based on the previous research findings, our hypotheses were:

Hypothesis la: Perceived individual learning support in the competency-based 
workplace e-learning system will have a positive effect on employees' intention to use the system.

Hypothesis 1b: The effect of perceived individual learning support on intention to use will be moderated by gender, such that the effect will be stronger for men than for women.

Hypothesis 1c: The effect of perceived individual learning support on intention to use will be moderated by age, such that the effect will be stronger for younger people than for older people.

Hypothesis 1d: The effect of perceived individual learning support on intention to use will be moderated by prior experiences, such that the effect will be stronger for those who have prior experiences of using online training than for those who have no such prior experiences.

\subsubsection{Perceived Peer Learning Support}

In the workplace training and human resource development literature, mentoring and peer relationship is recognized as one important form of employee developmental activity (others include employee assessment, job experiences, formal courses and programs, Noe, Wilk, Mullen \& Wanek, 1997). In the literature on distance learning and e-learning for human resource development, training researchers suggest that learner communication and collaboration in distance learning environment may address learners' social needs and therefore promote learners' satisfaction and motivation towards using online learning (Salas, Kosarzycki, Burke, Fiore \& Stone, 2002; Alavi, 1994). Furthermore, findings from research on success factors and acceptance of e-learning in an academic background also show that perceived interaction has a significant impact on students' intention to use e-learning (Pituch \& Lee, 2006; Liu, Chen, Sun, Wible \& Kuo, 2010). Thus, we hypothesized that perceived peer collaborative learning support in competency-based workplace e-learning systems would have a significant influence on employees' intention to use the system. To capture the characteristics of workplace peer relationship and learner collaboration, we broke down the perceived peer learning support into two aspects: perceived support for enhancing social ties and perceived support for promoting a norm of cooperation, based on Nahapiet \& Ghoshal's (1998) conceptualization of social capital. The gender, age, and prior experience differences in the effects of perceived peer learning support on intention to use were also hypothesized.

The effects of perceived support for enhancing social ties on intention to use moderated by the individual differences were hypothesized as the following:

Hypothesis 2a: Perceived support for enhancing social ties in the competency-based workplace e-learning system will have a positive effect on employees' intention to use the system.

Hypothesis 2b: The effect of perceived support for enhancing social ties on intention to use will be moderated by gender, such that the effect will be stronger for men than for women.

Hypothesis 2c: The effect of perceived support for enhancing social ties on intention to use will be moderated by age, such that the effect will be stronger for 
younger people than for older people.

Hypothesis 2d: The effect of perceived support for enhancing social ties on intention to use will be moderated by prior experiences, such that the effect will be stronger for those who have prior experiences of using online training than for those who have no such prior experiences.

The effects of perceived support for promoting a norm of cooperation on intention to use moderated by the individual differences were hypothesized as:

Hypothesis 3a: Perceived support for promoting a norm of cooperation in the competency-based workplace e-learning system will have a positive effect on employees'intention to use the system.

Hypothesis 3b: The effect of perceived support for promoting a norm of cooperation on intention to use will be moderated by gender, such that the effect will be stronger for men than for women.

Hypothesis 3c: The effect of perceived support for promoting a norm of cooperation on intention to use will be moderated by age, such that the effect will be stronger for younger people than for older people.

Hypothesis $3 d$ : The effect of perceived support for promoting a norm of cooperation on intention to use will be moderated by prior experiences, such that the effect will be stronger for those who have prior experiences of using online training than for those who have no such prior experiences.

Figure 1. Conceptual model

\section{RESEARCH DESIGN}

\subsection{Instrumentation and Conceptual Validation}

There were four constructs to be measured and modeled in this study. Perceived individual learning support refers to the extent to which competency-oriented workplace e-learning is perceived to be helpful for employees in assessing his/her position-specific competency and enhancing the effectiveness of acquiring work-related knowledge, skills, and ability. Measures of perceived individual learning support were based on 8 items adopted from Kirkpatrick \& Kirkpatrick (2006), Arbaugh (2000), Davis (1989), and Thurmond, Wambach \& Connors (2002). Perceived peer learning support refers to the extent to which competency-oriented workplace e-learning is perceived to be helpful for employees to enhance peer relationships and promote a norm of cooperation in workplace learning and development. Measures of perceived support for enhancing social ties were based on 6 items derived from van der Gaag (2005), Chiu, Hsu \& Wang (2006), and Borgatti \& Cross (2003). Measures of perceived support for promoting a norm of cooperation were composed of 3 items derived from Kankanhalli, Tan \& Wei (2005) and Noe, Wilk, Mullen \& Wanek (1997). The construct intention to use has been widely investigated in technology acceptance research, and this study adopted 3 items from Venkatesh \& Davis's (2000) and Kirkpatrick \& Kirkpatrick. (2006). 
After a preliminary instrumentation of these constructs, we conducted a pilot validation of the measures using Kankanhalli, Tan \& Wei's (2005) and Moore \& Benbasat's (1991) approach. 20 items were originally proposed for the four constructs: perceived individual learning support, perceived support for enhancing social ties, perceived support for promoting a norm of cooperation, and intention to use. Given definitions of all the constructs, the 20 items were presented in a random order to 12 subjects, 9 of whom were full-time employees holding a master's degree, and 3 of whom were doctoral students in education. The subjects were asked to posit each item to the most proper construct according to their understanding of the items and constructs (see Table 1). The objective of this pilot test was to ensure semantic clarity and discriminant validity of the items. Only items posited to the intended constructs with a high inter-subject agreement were preserved as the indictors of the constructs. After the pilot validation, a total of 15 items were preserved.

\subsection{Competency-Based E-Learning System Design}

A web-based competency-based e-learning system was developed for this study. The main instructional intervention provided in the system design was a competency-based learning model, which specified required competencies (including capabilities and knowledge component) of job positions according to relevant performance requirement or standard. The competency model was designed for an organization to clarify its training objectives, and for individuals to make sense of their work context. It was used as the pedagogical structure to: 1) drive curriculum design and learning resource organization, 2) identify individual learning needs and guide personalized learning activities, and 3) facilitate competency-oriented communication or networking. The system was designed to facilitate competency-based, self-directed, and socially constructed online learning activities in the workplace. Each individual may use the system to set up his/her learning target and perform adaptive learning activities under guidance. With the support of intelligent technology, real-time and personalized instructions and recommendations are continuously generated and sent to learners, to facilitate their learning processes towards the goal. In addition to the individual learning process, social learning and networking are facilitated in the developed system. Learners are able to contribute and evaluate learning resources, discuss their learning problems or experiences, and conduct peer evaluation of their performance, during which learners' work context, expertise, and proficiency can be identified with a view to facilitating their communication and networking in the learning community. A set of screenshots from the system is presented in Figure 2.

The effectiveness of the developed learning system has been shown in a control group study with positive results. The details of the design, development, and experimental evaluation of the system can be found in Wang, Jia, Sugumaran, Ran \& Liao (2010). To examine the research problem raised in this study, a survey was conducted to collect and analyze perceptions and reactions from more employee learners towards 
the competency-based learning system. A flash demonstration and PDF introduction of the system were also developed and provided at a website to allow easy access to the information. The survey questionnaire was created and posted to another website for free online surveys, with a link to the website of the system information.

\subsection{Sample}

The sampling method used in this survey was convenient sampling and snowball sampling. The questionnaire and system information were disseminated to a convenient sample of respondents and contacts in their social networks, and a reachable sample of clients of a training and consulting company in Mainland China. The demographics of sample respondents are outlined in Table 2.

\section{DATA ANALYSIS}

To estimate the measurement and structural coefficients simultaneously, this study adopted a structural equation modeling approach to test the hypothesized model. LISREL 8.7 (Jöreskog \& Sorbom, 2004) was employed to implement the modeling program. Following the two-stage strategy recommended by Anderson and Gerbing (1988), the measurement model was firstly tested via confirmatory factor analysis (CFA), and then the structural model was examined. Since the hypothesized moderating effects of individual characteristics were also to be tested in this study, the multi-group causal models comparison approach was adopted.

\subsection{Measurement Model}

To examine the measurement properties of the instrument, the initial measurement model consisting of 15 indictors loading on four constructs was tested against the sample data. The model fit indices values output by confirmatory factor analysis are given in Table 3. As seen in this table, the model fit of the initial model was acceptable except that the RMSEA value was a little high and the $\chi^{2} / \mathrm{df}$ value exceeded 2. The fit indices values of the revised model, which was derived from the initial model by dropping three of the six indictors (i.e. Q2, Q6, Q7) loading on perceived individual learning support (PILS) one by one following the modification index values, showed some improvement of model fit. Given that in the revised model each construct was measured by at least 3 items and all of the items were adopted from previous research (except PS-NOC2), we decided to adopt the revised measurement model. The items of the final instrument are given in Appendix I.

To validate the revised measurement model, we assessed its reliability and validity. Cronbach's $\alpha$ was assessed for reliability. Content validity, convergent validity, and discriminiant validity were also checked. Content validity was ensured by all of the items being adopted from previous published research. Convergent validity was assessed by examining the factor loadings $\left(\lambda_{\mathrm{i}}\right)$, the composite reliability $(\mathrm{CR})^{1}$, and the

${ }^{1} C R=\frac{\left(\sum \lambda_{i}\right)^{2}}{\left(\sum \lambda_{i}\right)^{2}+\sum \Theta_{i i}}$, where $\lambda_{\mathrm{i}}$ is the factor loadings, and $\Theta_{\mathrm{ii}}$ denotes the measurement error variances. 
average variance extracted (AVE) ${ }^{2}$ (Fornell \& Larcker, 1981; Hsu, Ju, Yen \& Chang, 2007; Chiu, Hsu \& Wang, 2006). Discriminant validity was verified by looking at the average variance extracted and the squared correlations between constructs using the approach recommended by Fornell \& Larcker (1981). Results of reliability and convergent validity analysis are presented in Table 4, and Table 5 gives data concerning discriminant validity.

As seen in Table 4, all the Cronbach's $\alpha$ values were higher than 0.7, showing satisfactory internal consistency reliability of the scales. For convergent validity, all the factor loadings were higher than 0.7 and significant, the four composite reliability values all exceeded 0.8, and all the four AVE values were higher than 0.5, showing satisfactory convergent validity of the scales against the criteria recommended by Fornell \& Larcker (1981). For discriminant validity, Fornell \& Larcker (1981) suggest that the average AVE values of any pair of constructs should be larger than the squared correlation between that pair of constructs. Table 5 shows that the four scales had acceptable discriminant validity.

\subsection{Structural Model}

To test the hypothesized relationships, the path coefficients among the latent variables were estimated via maximum likelihood by LISREL 8.7. The covariance matrix for the structural analysis is given in Appendix II. The results are presented in Figure 3. As seen in the path diagram, the hypotheses H1a and H3a were supported $\left(\gamma_{11}=0.75\right.$, $\left.\mathrm{t}=8.28 ; \gamma_{13}=0.71, \mathrm{t}=4.09\right)$, while $\mathrm{H} 2 \mathrm{a}$ was rejected with a significant negative effect $\left(\gamma_{12}=-0.47, \mathrm{t}=2.65\right)$. The three exogenous latent variables explained a total of $93 \%$ variance of the dependent variable.

\subsection{Multi-Group Structural Equation Modeling}

To test the hypothesized moderating effects of gender, age, and prior experiences, the multi-group causal models approach was adopted. In structural equation modeling literature, moderated structural equation models (MSEMs) have received increasing attention (Cortina, Chen \& Dunlap, 2001). Various strategies for testing latent variables interaction effects have been proposed such as multi-group causal models (Jöreskog, 1971; Bagozzi \& Yi, 1989; MacKenzie \& Spreng, 1992), and methods involving latent products (Kenny \& Judd, 1984; Jaccard \& Wan, 1995; Jöreskog \& Yang,1996; Mathieu \& Martineau, 1997; Cortina, Chen \& Dunlap, 2001; Li, Harmer, Duncan, Duncan, Acock \& Boles, 1998). The multi-group causal model approach was selected for this study, as the hypothesized moderators, i.e. gender, age, and experiences were categorical variables.

Following the procedures introduced in Steenkamp \& Baumgartner (1998), Chiou \& Lin (2009), Myers, Calantone, Page Jr \& Taylor (2000), Mullen (1995) and Hau,

${ }^{2} A V E=\frac{\sum \lambda_{i}^{2}}{\sum \lambda_{i}^{2}+\sum \Theta_{i i}}$, where $\lambda_{\mathrm{i}}$ is the factor loadings, and $\Theta_{\mathrm{ii}}$ denotes the measurement error variances. 
Wen \& Cheng (2004), the measurement invariance was first tested. After ensuring that the same measurement model held across different sub-samples, the comparisons of path coefficients across sub-samples were made. Each time, the entire sample was divided into two sub-samples according to values of the moderating variable. To test the hypothesized moderating effects of gender, the entire sample was split into the male group and the female group; for effects of age, the entire sample was divided into the younger group (35 or lower) and the older group (above 35); for effects of prior experience, the entire sample was split into the experienced group and the inexperienced group.

\subsubsection{Gender}

Following Chiou \& Lin's approach (2009), confirmatory factor analysis was implemented on the entire sample and the two sub-samples respectively. Table 6 (stage 1) shows that the four-factor measurement model fit the three samples acceptably. Then, following Steenkamp \& Baumgartner (1998), configural invariance and metric invariance were tested against the sample via multi-group confirmatory factor analysis. Configural invariance means that the factorial structure was supported in both populations (Myers, Calantone, Page Jr \& Taylor, 2000). Configural invariance was diagnosed by setting the factorial structure to have the same pattern and starting values across the two sub-samples (i.e. set LX=PS for the second group in LISREL). The fit indices values of the base model (unconstrained model) given in Table 6 (stage 2) suggest that the measurement model held configural invariance across the male group and the female group. Metric invariance means equal metrics on items across populations and scores or ratings observed on items can be meaningfully compared across populations (Steenkamp \& Baumgartner, 1998). Metric invariance was examined by setting the factor loading matrix to be invariant for the second group (i.e. set LX=IN in LISREL), following which the configural invariance was detected. Fit indices values and the chi-square changed based on the base model $\left(\triangle \chi^{2}=8.287, \triangle \mathrm{df}=8\right)$ given in Table 6 (stage 2 , the second line) was evidence that the measurement model holds metric invariance $\left(\triangle \chi^{2}\right.$ was not significant at given $\triangle$ df). In line with Steenkamp \& Baumgartner (1998), configural equivalence and metric equivalence was sufficient since the purpose of this study was to examine structural relationships across samples.

Figure 4 and Table 7 present the standardized path coefficients for the two sub-samples and the significance test of path differences across the two groups. Based on the results presented in Table 7, the difference in the effects of perceived individual learning support on intention to use $\left(\gamma_{11}\right)$ between the male group $\left(\gamma_{11}=0.86^{* *}, t=7.72\right)$ and the female group $\left(\gamma_{11}=0.59^{* *}, \mathrm{t}=5.56\right)$ was significant $\left(\Delta \chi_{(\Delta d f=l)}^{2}=4.214\right.$ was significant at $\mathrm{p}<0.05)$. The effect of perceived individual learning support on intention to use was stronger for men than for women, i.e., Hypothesis $1 \mathrm{~b}$ was supported. According to Table 7, the difference in the effects of perceived support for enhancing social ties on intention to use between the male group and the female group $\left(\Delta \chi_{(\Delta d f=1)}^{2}=-0.048\right)$, and the difference in the effects of perceived support for 
promoting a norm of cooperation on intention to use between the male group and the female group $\left(\Delta \chi_{(\Delta d f=1)}^{2}=-0.020\right)$ were not significant, which meant that Hypothesis $2 \mathrm{~b}$ and Hypothesis $3 \mathrm{~b}$ were not supported.

\subsubsection{Age}

The hypothesized moderating effects of age were also examined, firstly by diagnosing measurement invariance through multi-group confirmatory factor analysis and then by testing the path differences across sub-samples through the nested model comparison approach. Table 8 shows that the measurement model fit the entire sample, the younger group, and the older group acceptably except that the RMSEA value for the older group was higher than 0.1. Results in Table 8 indicate that the measurement instrument held configural invariance and metric invariance according to the model fit indices values and the chi-square changed $\left(\triangle \chi^{2}=9.5848^{\mathrm{ns}}, \triangle \mathrm{df}=8\right)$.

After ensuring that the measurement model could be applied to the two different sub-samples, multi-group comparisons of each of the three path coefficients $\left(\gamma_{11}, \gamma_{12}\right.$, $\left.\gamma_{13}\right)$ for the younger group and the older group were implemented. Figure 5 gives the standardized path coefficients for the two groups and Table 9 presents the constrained models comparison results. As shown in Table 9, no path coefficient was found to be significantly different across the younger group and the older group $\left(\Delta \chi_{(\Delta d f=1)}^{2}=0.643\right.$

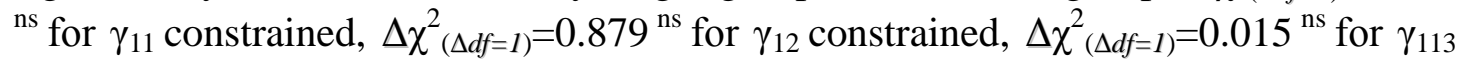
constrained). Therefore, hypotheses $1 \mathrm{c}, 2 \mathrm{c}$, and $3 \mathrm{c}$ were not supported.

\subsubsection{Prior Experience}

Table 10 presents the evidence of configural invariance and metric invariance of the measurement model across the experienced group and the inexperienced group $\left(\triangle \chi^{2}=1.179^{\mathrm{ns}}, \triangle \mathrm{df}=8\right)$. Figure 6 gives the standardized path coefficients for the two groups. Table 11 gives evidence that the effect of perceived individual learning support on intention to use was stronger for experienced users than for inexperienced users $\left(\Delta \chi_{(\Delta d f=l)}^{2}=5.656^{* *}\right)$. Thus, Hypothesis 1d was supported. However, no significant difference was found in the effects of perceived support for enhancing social ties and perceived individual learning support on intention to use across the experienced group and the inexperienced group $\left(\Delta \chi^{2}(\Delta d f=1)=1.724^{\mathrm{ns}}\right.$ for $\gamma_{12}$ constrained, $\Delta \chi^{2}(\Delta d f=1)=0.242^{\mathrm{ns}}$ for $\gamma_{13}$ constrained). Therefore hypotheses $2 \mathrm{~d}$ and $3 \mathrm{~d}$ were not supported.

As a summary, Table 12 outlines all the results of the hypotheses testing.

\section{DISCUSSION}

The purpose of this research was to examine employees' perceptions and acceptance of competency-based workplace e-learning systems, an issue that has not been adequately addressed in the current literature. The basic assumption was that perceived usefulness of performance oriented learning design for self-directed and collaborative learning embedded in e-learning systems would be helpful for diffusion 
of the e-learning systems to adult learners. Built on two bodies of literature, namely that of technology acceptance and that of training and instructional design, a conceptual model hypothesizing causal relationships between individual learning and peer learning support and intention to use was proposed and tested against a sample data collected from work settings in mainland China. Results of structural equation modeling and multi-group structural equation modeling applied on the sample data suggested that some of the research hypotheses were supported, while others lacked evidence to be accepted. The hypotheses testing results are discussed below.

\section{Individual learning support and individual characteristics}

Perceived individual learning support was found to have a significant positive impact on respondents' intention to use the competency-oriented e-learning systems. This result was reasonable and consistent with widely validated findings in technology acceptance research. In this study, perceived individual learning support was defined as the extent to which the competency-oriented workplace e-learning system was perceived to be helpful for respondents in identifying their knowledge gaps and learning needs based on the competency model, in constructing knowledge in their work context, and in enhancing effectiveness of their work-related learning. The result suggests that if the competency and performance oriented learning design is thought to be useful for improving learners' self-directed on-the-job learning process and performance, the technological systems delivering those pedagogical design elements tends to be adopted.

Results of the multi-group analysis indicated that the effect of perceived individual learning support on intention to use was significantly stronger for men than for women. In the technology acceptance literature, it has been repeated shown that perceived usefulness in determining behavioral intention is more salient for men than for women (Venkatesh \& Morris, 2000; Sun \& Zhang, 2006; Venkatesh, Morris, Davis \& Davis, 2003). Venkatesh \& Morris (2000) employed research on gender schema differences in decision making processes and gender differences in the salience of outcomes as determinants of behavior to rationalize their empirical findings. In this study, the empirically supported gender difference in employees' decision making concerning acceptance of competency-based e-learning technology suggests that instrumentally useful pedagogical design elements such as competency-oriented learning assessment, goals setting, and learning materials organization provided in technological systems may increase the success of workplace e-learning initiatives in a male-predominant workforce.

The hypothesized age difference in the effect of individual learning support on acceptance was not found in this research. However previous research findings suggest that the effect of perceived usefulness or system performance expectancy on behavioral intention is stronger for younger people than for older people, either in adoption of general workplace technology (Sun \& Zhang, 2006; Venkatesh, Morris, Davis \& Davis, 2003) or in mobile learning (Wang, Wu \& Wang, 2009). Lack of 
evidence for greater salience of outcome expectancy as a determinant of e-learning acceptance for the younger people in this study was unexpected, and the reason is unknown, which implies that further investigations may be needed.

The hypothesized experience difference in the effect of perceived individual learning support on intention to use was supported. The effect of individual learning support expectancy on acceptance was stronger for respondents who had prior experience of using online training courses than for respondents who had no such prior experience. Although in the information system acceptance literature the moderating effect of prior experience on the relationship between perceived usefulness and behavioral intention is usually not directly hypothesized and evidenced, empirical research on e-learning for adult job-relevant training widely suggests that e-learning can be a positive experience that leads to improved perceptions and positive attitudes following use, which in turn may increase participants' intention to use it again (Welsh, Wanberg, Brown \& Simmering, 2003; Gold, 2001; Heinzen \& Alberico, 1990; Johnson, Lohman, Sharp \& Krenz, 2000). The finding that the effect of individual learning support on intention to use was stronger for experienced learners than for inexperienced learners suggest that human resource practitioners may consider improving employees' online learning experiences before adopting e-learning initiatives.

\section{Peer learning support and individual characteristics}

The results indicate that the two aspects of peer learning support: perceived support for enhancing social ties and perceived support for promoting a norm of cooperation, both had a significant impact on intention to use. Contrary to our hypothesis, perceived support for enhancing social ties was found to have a significant negative effect on behavioral intention. The negative effect means that if the competency-oriented workplace e-learning system is perceived to be able to promote interaction and close relationships between colleagues, then the system tends not to be used. The negative effect of supporting social networking on intention to use the system may possibly be attributed to adult learners' perceptions of the online learning system as a kind of social software. The perceived support for social networking in the online learning system means that the system will facilitate explicit exchange and expression of employees' social information such as identity, role, attitude, and personal relationships in a shared space (Shirky, 2003; Boyd, 2003). This kind of perception may lead to adult's distrust of the system due to adult learners' characteristics, especially in a Chinese cultural setting. Another possible reason for the negative effect may be related to adult learners' working habits and workloads as suggested in Choy \& Ng's (2007) research on part-time students using a wiki for online learning. While there are no direct research findings regarding the negative effect of adult learners' perceptions of social networking support on their intention to use the online learning system, further research on this issue is needed.

The positive effect of perceived support for promoting a norm of cooperation on 
intention to use was evidenced in our empirical findings and hypothesized without validation in the literature such as Salas, Kosarzycki, Burke, Fiore \& Stone (2002) and Alavi (1994). Tynjala \& Hakkinen (2005) posit that participating in workplace e-learning is a social process involving adult learners' interaction and communication. Salas, Kosarzycki, Burke, Fiore \& Stone (2002) hypothesize that learner communication and collaboration in a distance learning environment may address adult learners' social needs and therefore promote learners' satisfaction of, and motivation towards using, online learning. The positive effect of perceived support for promoting a norm of cooperation on intention to use supported in this study suggests that workplace learning designs that promote peer mentoring and teamwork and collaboration in on-the-job learning, such as position-guided and competency-specific peer discussion, consulting, and coaching, are critical to the success of technological systems that are designed to deliver those learning interventions. Therefore, e-learning designers may need to consider supporting competency-oriented peer discussion and collaboration activities in the learning platforms, e.g., searches for peer learners based on their expertise or competencies.

Gender, age, or prior experience difference was not found in the effects of peer learning support and intention to use the competency-based workplace e-learning system. There is a lack of research that operationalizes peer learning support as support towards promoting social ties and support towards enhancing a norm of cooperation and examines their effects on intention to use e-learning. Further studies may be needed to examine the moderating effects of individual differences on the relationship between social learning support and acceptance of learning technologies.

\section{CONCLUSION}

Fierce competition, globalization, and technology innovation have forced organizations to search for new ways to improve competitive advantage. E-learning is increasingly being used by companies as an emergent approach for enhancing the skills of knowledge workers. In the meantime, the history of e-learning is still short, and it can be characterized as more technology-driven than problem-driven or learner-driven. Furthermore, it has been emphasized that the mainstream conceptualizations of e-learning developed in the institutional context are not transferable to workplace learning which is built on adult learners and in work situations (Wang, Ran, Liao \& Yang, 2010).

Competency-based learning has recently been incorporated into e-learning applications in the workplace context. Most efforts have emphasized technical implementation and ignored pedagogical and behavioral issues that are necessary for design of effective competency-based learning systems. This study was conducted to examine instructional design factors that might influence adult learners' perceptions and reaction towards this technology-delivered pedagogical innovation. Support for learning is essential in the design of any e-learning environment, including the workplace. The study has focused on the support of competency-oriented, 
self-directed, and socially constructed online learning in the workplace. One challenge for workplace e-learning is how to link employees' personal development with organizational learning and development. This study uses the competency model as the pedagogical structure for curriculum design and learning resource management. This model helps identify individual needs and direct personalized navigation in the web-based learning environment. At the same time, it helps identify individual expertise and facilitates competency-oriented social learning and networking. The empirical results suggest that perceived usefulness of work-integrated pedagogical design in terms of improving self-directed learning processes and promoting collaboration among colleagues has positive influences on employees' behavioral intention to use the e-learning system that is developed with competency-based pedagogical innovations. Gender and prior experience differences in the effect of individual learning support on behavioral intention are also found. Findings of this research contribute to the current endeavors to integrate competency-based instruction and training for adults with advanced e-learning technologies from a behavioral perspective, and provide implications for instructional design of workplace learning technologies.

Limitations of this research are twofold. First, the sampling method was not rigorously random and the sample size was limited. The findings of this research, which resulted from the convenient sample data, have limited generalizability. At the same time, the relatively small sample size contrasted to the rigorous requirements of a structural equation modeling technique may have led to biased results. Second, results of this research are based on self-reported data collected solely via a questionnaire survey. Rigorous procedures were implemented to validate the reliability, convergent validity, and discriminiant validity of the scales; however, the reliability and validity of the data also relied on psychometric techniques and the results were subject to subjectivity.

The competency-based learning approach incorporated in e-learning systems design is still in a state of academic validation and not widely practiced. The results of this research regarding users' perceptions and acceptance of competency-based workplace e-learning systems are to be further validated by empirical studies and industrial practices. Further work will consider longitudinal research based on advancements in industrial practices. Investigations will be based on large representative sample data. Multiple data sources such as data collected through interview and observation will be used for in-depth analysis.

\section{ACKNOWLEDGEMENT}

This research is supported by a UGC GRF Grant (No. 717708) from the Hong Kong SAR Government and two Seeding Funds for Basic Research (No. 200911159142) from The University of Hong Kong.

\section{REFERENCES}


1. Admiraal, W. \& Lockhorst, D. (2009). E-Learning in Small and Medium-sized Enterprises across Europe. International Small Business Journal, 27(6), 743-767.

2. Alavi, M. (1994). Computer-mediated collaborative learning: An empirical evaluation. MIS Quarterly, 18(2), 159-174.

3. Anderson, J. C. \& Gerbing, D. W. (1988). Structural Equation Modeling in Practice: A Review and Recommended Two-Step Approach. Psychological Bulletin, 103(3), 41-423.

4. Arbaugh, J. B. (2000). Virtual classroom characteristics and student satisfaction with internet-based MBA courses. Journal of Management Education, 24(1), 32-54.

5. Bagozzi, R.P. \& Yi,Y. (1989). On the use of structural equation models in experimental designs. Journal of Marketing Research, 26(3), 271-284.

6. Bentler, P.M. (1988). Theory and Implementation of EQS: A structural Equations Program. Sage, Newbury Park, CA.

7. Bersin, J. (2002). Start measuring your e-learning programs now, LineZine. Available at: http://www.linezine.com/7.2/articles/jbsmyelpn.htm (accessed 10 May 2010).

8. Bonanno, P. \& Kommers, P. A. M. (2008). Exploring the influence of gender and gaming competence on attitudes towards using instructional games. British Journal of Educational Technology, 39(1), 97-109.

9. Borgatti, S. P. \& Cross, R. (2003). A relational view of information seeking and learning in social networks. Management Science, 49(4), 432-445.

10. Boyd, S. (2003). Are you ready for social software? Darwin Magazine, Available at:http://www.darwinmag.com/read/050103/social.html (accessed 10 May 2010)

11. Brown, L., Murphy, E., \& Wade, V. (2006). Corporate e-Learning: Human Resource Development implications for large and small organisations, Human Resource Development international, 9(3), 415-427.

12. Browne, M. W. \& Cudeck, R. (1993). Alternative ways of assessing model fit. In Testing Structural Equation Models. K. A. Bollen and J. S. Long (eds.), Sage, Newbury Park, CA. 136-162.

13. Burgess, J. R. D. \& Russell, J. E. A. (2003). The effectiveness of distance learning initiatives in organizations. Journal of Vocational Behavior, 63, 289-303.

14. Burgoyne, J.G. (1993). The competence movement: Issues, stakeholders and prospects. Personnel Review, 22 (6), 6-13.

15. Burke, L. \& Hutchins, H. (2007). Training transfer: An integrative review. Human Resource Development Review, 6(3), 263-296.

16. Camuffo, A. \& Gerli, F. (2004). An integrated competency-based approach to management education: an Italian MBA case study. International Journal of Training \& Development, 8(4), 240.

17. Carmines, E. \& McIver, J. (1981). Analyzing models with unobserved variables: Analysis of covariance structures. In G. Bohrnstedt \& E. Borgatta (Eds.), Social measurement: Current issues, 65-115. Beverly Hills, CA: Sage.

18. Chang, C. (2006). Development of Competency-Based Web Learning Material and Effect Evaluation of Self-Directed Learning Aptitudes on Learning 
Achievements. Interactive Learning Environments, 14(3), 265 - 286

19. Chen, I. J., Yang, K., Tang, F., Huang, C., \& Yu, S. (2007). Applying the technology acceptance model to explore public health nurses' intention towards web-based learning: A cross-sectional questionnaire survey. International Journal of Nursing Studies, 45(6), 869-878.

20. Chiou, H., \& Lin, P.-F. (2009). Principles and Application of Structural Equation Modeling. Beijing: China Light Industry Press.

21. Chiu, C.-M. \& Wang, E.T.G. (2008). Understanding Web-based learning continuance intention: The role of subjective task value. Information and Management, 45(3), 194-201.

22. Chiu, C.-M., Hsu, M.-H., \& Wang, E.T.G.. (2006). Understanding knowledge sharing in virtual communities: An integration of social capital and social cognitive theories. Decision Support Systems, 42(3), 1872-1888.

23. Chiu, C.-M.,Sun, S.-Y., Sun, P.-C., \& Ju, T.L. (2007). An empirical analysis of the antecedents of web-based learning continuance. Computers and Education, 49(4), 1224-1245.

24. Cho, V., Cheng, T.C.E., \& Lai, W.M.J. (2009). The role of perceived user-interface design in continued usage intention of self-paced e-learning tools. Computers and Education, 53(2), 216-227.

25. Choy, S. O. \& Ng, K. C. (2007). Implementing wiki software for supplementing online learning. Australasian Journal of Educational Technology, 23(2), 209-226.

26. Clark, R. C. \& Mayer, R. E. (2008). E-Learning and the science of instruction: proven guidelines for consumers and designers of multimedia learning, San Francisco, California, Pfeiffer.

27. Colquitt, J. A., LePine, J. A., \& Noe R.A. (2000). Toward an integrative theory of training motivation: a meta-analytic path analysis of 20 years of research. Journal Applied Psychology, 85, 678-707.

28. Cortina, J. M., Chen, G., \& Dunlap, W. P. (2001). Testing interaction effects in LISREL: Examination and illustration of available procedures. Organizational Research Methods, 4, 324-360.

29. Davis, F.D. (1989). Perceived usefulness, perceived ease of use, and user acceptance of information technology, MIS Quarterly 13(3), 318-340.

30. DeRouin, R. E., Fritzsche BA, \& Salas E. (2004). Optimizing e-learning: Research-based guidelines for learner-controlled training. Human Resource Management, 43, 147-162.

31. Etezadi-Amolo, J. \& Farhoomand, A.F., (1996). A structural model of end user computing satisfaction and user performance. Information and Management, 30 (2), 65-73.

32. Fleishman, E.A.F. (1997). Foreward. In J. K. Ford, S. W. J. Kozlowski, K. Kraiger, E. Salas, \& M. S. Teachout (Eds.), Improving training effectiveness in work organizations: ix-x. Mahwah, NJ: Erlbaum.

33. Folberg, R., Antonioli, D.A., \& Alexander, C.B. (2002). Competency-based residency training in pathology: Challenges and opportunities. Human Pathology, 33(1), 3-6. 
34. Ford, J. K., Kozlowski, S.W.J., Kraiger, K., Salas, E., \& Teachout, M. S. (1997). Improving training effectiveness in work organizations. Mahwah, N.J.: Lawrence Erlbaum.

35. Fornell, C. R. \& Larcker, D. F. (1981). Evaluating structural equation models with unobservable variables and measurement error. Journal of Marke Wang ting Research, 18, 39-50.

36. Gold, S. (2001). A constructivist approach to online training for online teachers. Journal of Asynchronous Learning Networks, 5 (1), 35-57.

37. Hashim, J. (2008). Factors influencing the acceptance of web-based training in Malaysia: applying the technology acceptance model, International Journal of Training and Development, 12(4), 253-264.

38. Hau, K., Wen Z., \& Cheng, Z. (2004). Structural Equation Model and Its Applications. Beijing: Educational Science Publishing House.

39. Hayashi, A., Chen, C., Ryan, T., \& Wu, J. (2004). The role of social presence and moderating role of computer self efficacy in predicting the continuance usage of e-learning systems. Journal of Information Systems Education, 15(2), 139-154.

40. Heinzen, T. E. \& Alberico, S. M. (1990). Using a creativity paradigm to evaluate teleconferencing. American Journal of Distance Education, 4, 3-12.

41. Henry, P. (2001). E-learning technology, content and services. Education + Training, 43, 249-255.

42. Hsu, M.-H., Ju, T.L., Yen, C.-H., \& Chang, C.-M. (2007). Knowledge sharing behavior in virtual communities: The relationship between trust, self-efficacy, and outcome expectations. International Journal of Human Computer Studies, 65(2), 153-169.

43. Hu, Li-Tze \& Bentler, P.M. (1999). Cutoff Criteria for Fit Indexes in Covariance Structure Analysis: Conventional Criteria versus New Alternatives, Structural Equation Modeling, 6(1), 1-55.

44. Jaccard, J. \& Wan, C. K. (1995). Measurement error in the analysis of interaction effect between continuous predictors using multiple regression Multiple indicator and structural equation approaches. Psychological Bulletin, 117, 348-357.

45. Johnson, L. A., Lohman. M. C., Sharp, J. D., \& Krenz, T. C. (2000). Continuing dental education via an Interactive Video Network: Course development, implementation and evaluation. Journal of Educational Media, 25, 129-40.

46. Jöreskog, K. G. (1971). Simultaneous factor analysis in several populations. Psychometrika, 36, 409-426

47. Jöreskog, K. G. \& Sörbom, D. (2004). LISREL 8.7 for Windows [Computer software]. Lincolnwood, IL: Scientific Software International.

48. Jöreskog, K. G. \& Yang, F. (1996). Nonlinear structural equation models: The Kenny-Judd model with interaction effects. In G. A. Marcoulides\&R. E. Schumacker (Eds.), Advanced structural equation modeling techniques, Hillsdale, NJ: Lawrence Erlbaum, 57-88.

49. Kankanhalli, A., Tan, B., \& Wei, K.-K. (2005). Contributing knowledge to electronic knowledge repositories: An empirical investigation. MIS Quarterly, 29(1), 113-143. 
50. Kenny, D. \& Judd, C. M. (1984). Estimating the nonlinear and interactive effects of latent variables. Psychological Bulletin, 96, 201-210.

51. King, W. R. \& He, J. (2006). A meta-analysis of the technology acceptance model. Information \& Management 43 (6), 740-755.

52. Kirkpatrick, D. L. \& Kirkpatrick, J. D. (2006). Evaluating Training Programs (Third Edition ed.). San Francisco, CA: Berrett-Koehler Publishers, Inc.

53. Klein, H. J., Noe, R.A., \& Wang, C. (2006). Motivation To Learn and Course Outcomes: The Impact of Delivery Mode, Learning Goal Orientation, and Perceived Barriers and Enablers, Personnel Psychology, 59, 665-702.

54. Lau, S.H. \& Woods, P. C. (2008). An investigation of user perceptions and attitudes towards learning objects. British Journal of Educational Technology, 39(4), 685-699.

55. Lee M.-C. (2010). Explaining and predicting users' continuance intention toward e-learning: An extension of the expectation-confirmation model. Computers and Education,54(2), 506-516.

56. Lee, B.-C., Yoon, J.-O., \& Lee, I. (2009). Learners' acceptance of e-learning in South Korea: Theories and results. Computers and Education, 53(4), 1320-1329.

57. Leyking, K., Chikova, P., \& Loos, P. (2007). Competency- and Process-Driven e-Learning - a Model-Based Approach. The Electronic Journal of e-Learning, 5(3), 183-194.

58. Li, F., Harmer, P., Duncan, T. E., Duncan, S. C., Acock, A., \& Boles, S. (1998). Approaches to testing interaction effects using structural equation modeling methodology. Multivariate Behavioral Research, 33, 1-39.

59. Limayem, M. \& Cheung, C.M.K. (2008). Understanding information systems continuance: The case of Internet-based learning technologies. Information and Management, 45(4), 227-232.

60. Little, B. (2010). E-Learning Budgets Increase in the U.K.'s Voluntary Sector.

E-learning Magazine. Available at:

http://www.elearnmag.org/subpage.cfm?section=opinion \&article=140-1 (Accessed 29 June 2010).

61. Liu, I. F., Chen, M.C., Sun, Y.S., Wible, D., \& Kuo, C. H. (2010). Extending the TAM model to explore the factors that affect Intention to Use an Online Learning Community. Computers and Education, 54(2), 600-610.

62. Long, D.M. (2000). Competency-based residency training: the next advance in graduate medical education. Academic Medicine, 75, 1178-83.

63. Lu, H. P. \& Chiou, M.-J. (2010). The impact of individual differences on e-learning system satisfaction: A contingency approach, 41(2), 307-323.

64. MacKenzie, S.B. \& Spreng. R.A. (1992). How does motivation moderate the impact of central and peripheral processing on brand attitudes and intentions. Journal of Consumer Research, 18(1), 519-529.

65. Majchrzak, A., Rice, R. E., Malhotra, A., King, N., \& Ba, S. (2000). Technology adaptation: The case of a computer-supported inter-organizational virtual team. MIS Quarterly, 24(4), 569-600.

66. Mathieu, J.E. \& Martineau, J.W. (1997). Individual and situational influences in 
training motivation. In J. K. Ford, S. W. J. Kozlowski, K. Kraiger, E. Salas, \& M. S. Teachout (Eds.), Improving training effectiveness in work organizations: $i x-x$. Mahwah, NJ: Erlbaum.

67. Merriam, S. (2001). Androgeny and self-directed learning: Pillars of adult learning theory. In Merriam, S. (Ed.), The new update on adult learning theory, San Francisco: Jossey-Bass, 3-13.

68. Moore, G. C. \& Benbasat, I. (1991). Development of an Instrument to Measure the Perceptions of Adopting an Information Technology Innovation. Information Systems Research 2(3), 173-191.

69. Mullen, M. R. (1995). Diagnosing Measurement Equivalence in Cross-National Research. Journal of International Business Studies, 26(3), 573-596.

70. Murray, D. (2001). E-Learning for the Workplace: Creating Canada's Lifelong Learners. The Conference Board of Canada.

71. Myers, M.B. Calantone, R.J., Page Jr, T.J., \& Taylor, C. R. (2000). Academic Insights: An application of Multiple-Group Causal Models in Assessing Cross-Cultural Measurement Equivalence, Journal of International Marketing, 8, 108-121.

72. Nahapiet, J. \& Ghoshal, S. (1998). Social capital, intellectual capital, and the organizational advantage. Academy of Management Review, 23, 242-266.

73. Netteland, G., Wasson, B., \& Morch, A. I. (2007). E-learning in a large organization: A study of the critical role of information sharing. Journal of Workplace Learning, 19(6), 392-411.

74. Ngai, E.W.T., Poon, J.K.L., \& Chan, Y.H.C. (2007). Empirical examination of the adoption of WebCT using TAM. Computers and Education, 48(2), 250-267.

75. Noe, R. A., Wilk, S. L., Mullen, E. J., \& Wanek, J. E. (1997). Employee development: Construct validation issues. In J. K. Ford, S. W. J. Kozlowski, K. Kraiger, E. Salas, \& M. S. Teachout (Eds.), Improving training effectiveness in work organizations, 153-189. Mahwah, NJ: Erlbaum

76. Nonaka, I. \& Takeuchi, H. (1995). The Knowledge-Creating Company: how Japanese companies create the dynamics of innovation, New York: Oxford University Press

77. Ong, C. S., Lai, J. Y., \& Wang, Y. S. (2004). Factors affecting engineers' acceptance of asynchronous e-learning systems in high-tech companies, Information \& Management, 41(6), 795-804.

78. Park, J. H. \& Wentling, T. (2007). Factors associated with transfer of training in workplace e-learning. Journal of Workplace Learning, 19(5), 311-329.

79. Patterson, D., Jung, G., \& Broadhead, G. (2009). The UK e-learning market 2009. Learning Light Limited. Available at: http://e-learningcentre.co.uk/Resource/CMS/Assets/5c10130e-6a9f-102c-a0be-00 3005bbceb4/UK\%20e-learning\%20market\%20report\%20by\%20Learning\%20Lig ht\%202009\%20(1).pdf (Accessed 29 June 2010).

80. Pituch, K.A. \& Lee, Y.-k. (2006). The influence of system characteristics on e-learning use. Computers and Education, 47(2), 222-244.

81. Rabak, L. \& Cleveland-Innes, M. (2006). Acceptance and resistance to corporate 
e-learning: A case from the retail sector. Journal of Distance Education, 21(2), 115-134.

82. Ricciardi, J. N. (2005). Achieving human service outcomes through competency-based training: A guide for managers. Behavior Modification, 29, 488-507.

83. Roca, J.C. \& Gagne, M. (2008). Understanding e-learning continuance intention in the workplace: A self-determination theory perspective. Computers in Human Behavior, 24(4), 1585-1604.

84. Rosenberg, M. C. (2006). Beyond E-Learning, San Fransisco, Pfeiffer.

85. Rubin, N.J., Bebeau, M., Leigh, I.W., Lichtenberg, J.W., Nelson, P.D., Portnoy, S., Smith, I.L., \& Kaslow, N.J. (2007). The competency movement within psychology: An historical perspective. Professional Psychology: Research and Practice, 38, 452-462.

86. Salas, E., Kosarzycki, M. P., Burke, C. S., Fiore, S. M., \& Stone, D. L. (2002). Emerging themes in distance learning research and practice: Some food for thought. International Journal of Management Reviews.

87. Schmidt, A. (2008). Enabling learning on demand in semantic work environments: The learning in process approach. In J. Rech, B. Decker, \& E. Ras, (Eds.), Emerging Technologies for Semantic Work Environments: Techniques, Methods, and Applications. IGI Publishing.

88. Servage, L. (2005). Strategizing for workplace e-Learning: Some critical considerations, Journal of Workplace Learning, 17(5/6), 304-317.

89. Shirky, C. (2003). A Group Is Its Own Worst Enemy. In Spolsk, Joel(Ed), The best software wetting I: selected and introduced by Joel Spolsk. New York: Apress.

90. Sicilia, M.A. \& Naeve, A. (2007). Competencies and organizational learning: a conceptual framework. In Sicilia, M.A. (Ed), Competencies in organizational e-learning: concepts and tools, Hershey: Information Science Publishing, 1-9.

SkillSoft. (2010). What Return On Investment Does e-Learning Provide? SkillSoft Inc. available at:

http://www.skillsoft.com/infocenter/whitepapers/documents/valuemeasurement_p aper.pdf (accessed 28 June 2010).

92. Steenkamp, Jan-Benedict E.M., \& Hans Baumgartner (1998). Assessing Measurement Invariance in Cross-National Consumer Research. Journal of Consumer Research, 25 (June), 78-90.

93. Sun, H. \& Zhang, P. (2006). The role of moderating factors in user technology acceptance. International Journal of Human Computer Studies, 64(2), 53-78.

94. Taylor, S. \& Todd, P. A. (1995). Assessing IT Usage: The Role of Prior Experience. MIS Quarterly, 19(2), 561-570.

95. Thurmond, V. A., Wambach, K., \& Connors, H. R. (2002). Evaluation of student satisfaction: determining the impact of a web-based environment by controlling for student characteristics. The American Journal of Distance Education, 16(3), 169-189

96. Tynjälä, P. \& Häkkinen, P. (2005). E-Learning at work: theoretical underpinnings and pedagogical challenges. The Journal of Workplace Learning, 17(5/6), 
318-336.

97. van der Gaag, M. P. J. (2005). Measurement of individual social capital. Unpublished Ph.D. thesis. Groningen: University of Groningen.

98. van Raaij, E.M. \& Schepers, J.J.L. (2008). The acceptance and use of a virtual learning environment in China. Computers and Education,50(3), 838-852.

99. Vaughan, K. \& MacVicar, A. (2004). Employees' pre-implementation attitudes and perceptions to E-learning: A banking case study analysis. Journal of European Industrial Training, 28(5), 400-413.

100. Venkatesh, V. \& Davis, F. D. (2000). A Theoretical Extension of the Technology Acceptance Model: Four Longitudinal Field Studies. Management Science, 46(2), 186-204.

101. Venkatesh, V., Morris, M. G., Davis, G. B., \& Davis, F. D. (2003). User acceptance of information technology: toward a unified view. MIS Quarterly, 27(3), 425-478.

102. Venkatesh, V ., \& Morris, M.G . (2000). Why Don't Men Ever Stop to Ask For Directions? Gender, Social Influence, and Their Role in Technology Acceptance and Usage Behavior. MIS Quarterly, 24(1), 115-139.

103. Wang, H.-Y. \& Wang, Y.-S. (2008). Gender differences in the perception and acceptance of online games. British Journal of Educational Technology, 39(5), 787-806.

104. Wang, M., Jia, H., Sugumaran, V., Ran, W., \& Liao, J. (2010). A Web-Based Learning System for Software Test Professionals. IEEE Transactions on Education, in press, DOI: 10.1109/TE.2010.2051546

105. Wang, M. (2010). Integrating organizational, social, and individual perspectives in Web 2.0-based workplace e-learning. Information Systems Frontier (in press).

106. Wang, M., Ran, W., Liao, J., \& Yang, S.J.H. (2010). A Performance-Oriented Approach to Workplace E-Learning Systems Development , Educational Technology \& Society, in press.

107. Wang, Y.-S., Wu, M.-C., \& Wang, H.-Y. (2009). Investigating the determinants and age and gender differences in the acceptance of mobile learning. British Journal of Educational Technology, 40 (1), 92-118.

108. Welsh, E. T., Wanberg, C. R., Brown, E. G., \& Simmering, M. J. (2003). E-learning: Emerging uses, empirical results and future directions. International Journal of Training and Development, 7, 245-258.

109. Wenger, E. (2000). Communities of practice: learning, meaning, and identity, Cambridge, U.K.; New York, N.Y.: Cambridge University Press.

110. Woelk, D. \& Lefrere, P. (2002). Technology for performance-based lifelong learning. In R. Kinshuk et al. (Eds.), Proceedings of International Conference on Computers in Education, 92-96, Los, Alamitos: IEEE Computer Society.

111. Yeung, P. \& Jordan, E. (2006). Understanding the continued usage of business e-learning courses in HK corporations. In D. Kumar \& J. Turner (Eds.), International federation for information processing, volume 210, Education For The 21st Century-Impact Of ICT and Digital Resources, WCC 2006 Santiago, 
Chile, 245-254. Boston: Springer.

\section{Figures}

Figure 1. System architecture

Figure 2. Main concepts with relation cardinalities

Figure 3. A part of learning ontology for the Testing Unit

Figure 4. Reasoning with learning ontology

Figure 5. A personalized learning syllabus

Figure 6. Screenshots of the prototype

Figure 7. Visualization of the ontology using Protégé and "Jambalaya tab"

\section{Tables}

Table 1. Concepts and their Relations

Table 2. Evaluation of the e-learning systems

Table 3. Preference on the e-learning systems 


\section{$\underline{\text { Figures }}$}

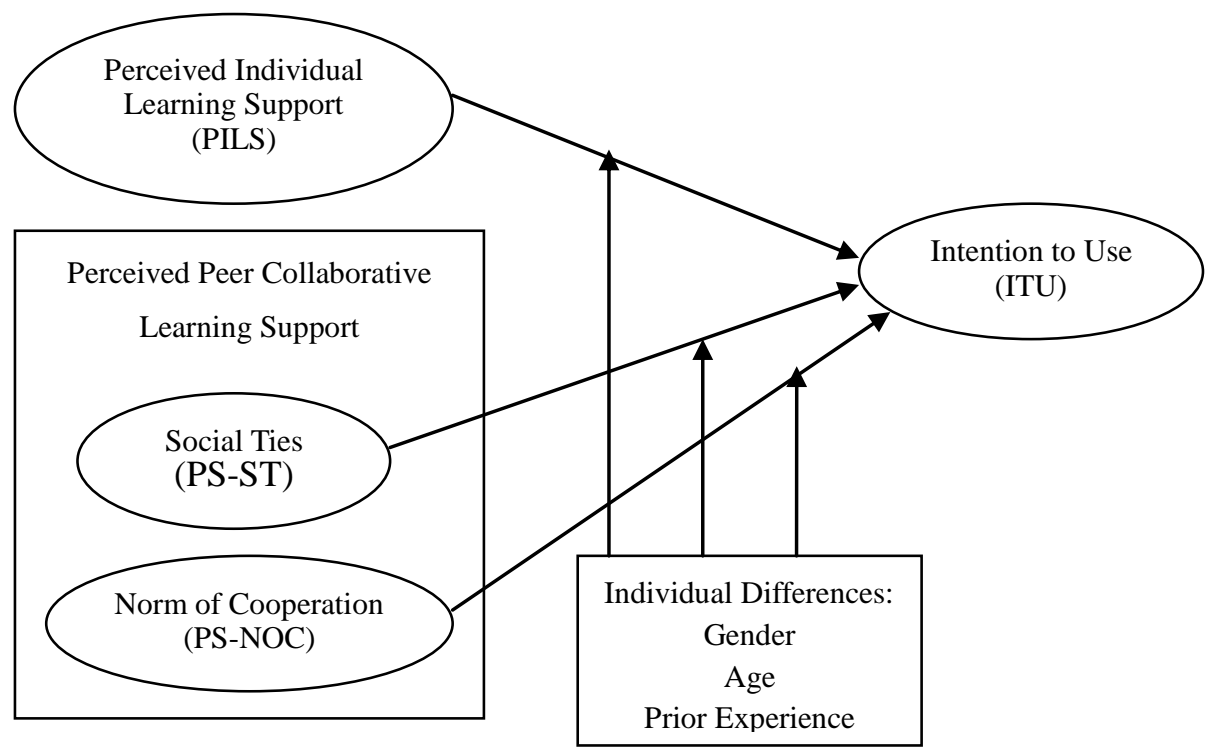

PS-ST: Perceived support for enhancing Social Ties

PS-NOC: Perceived support for promoting a Norm of Cooperation

Figure 1. Conceptual model

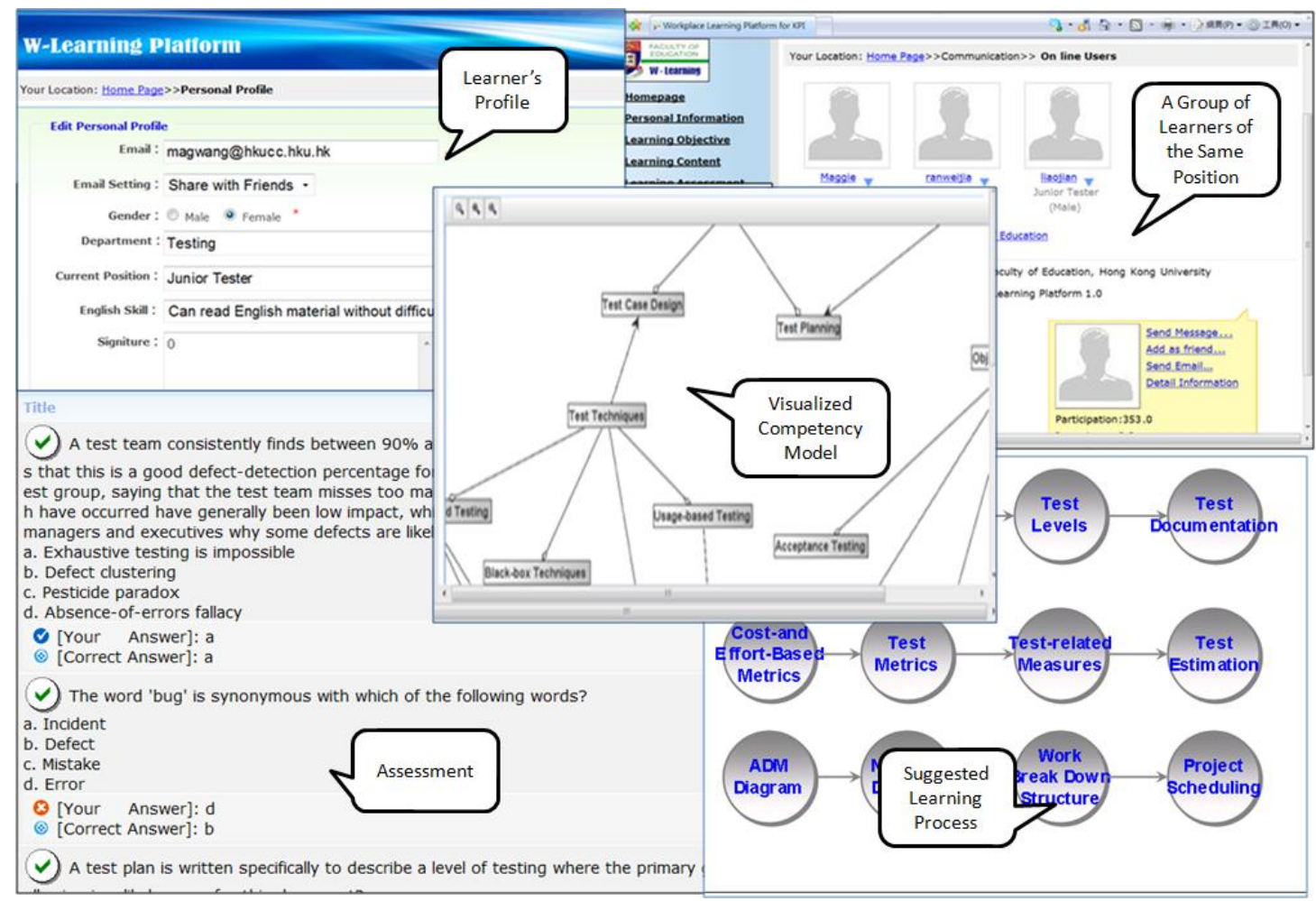

Figure 2. Screenshots of the system 


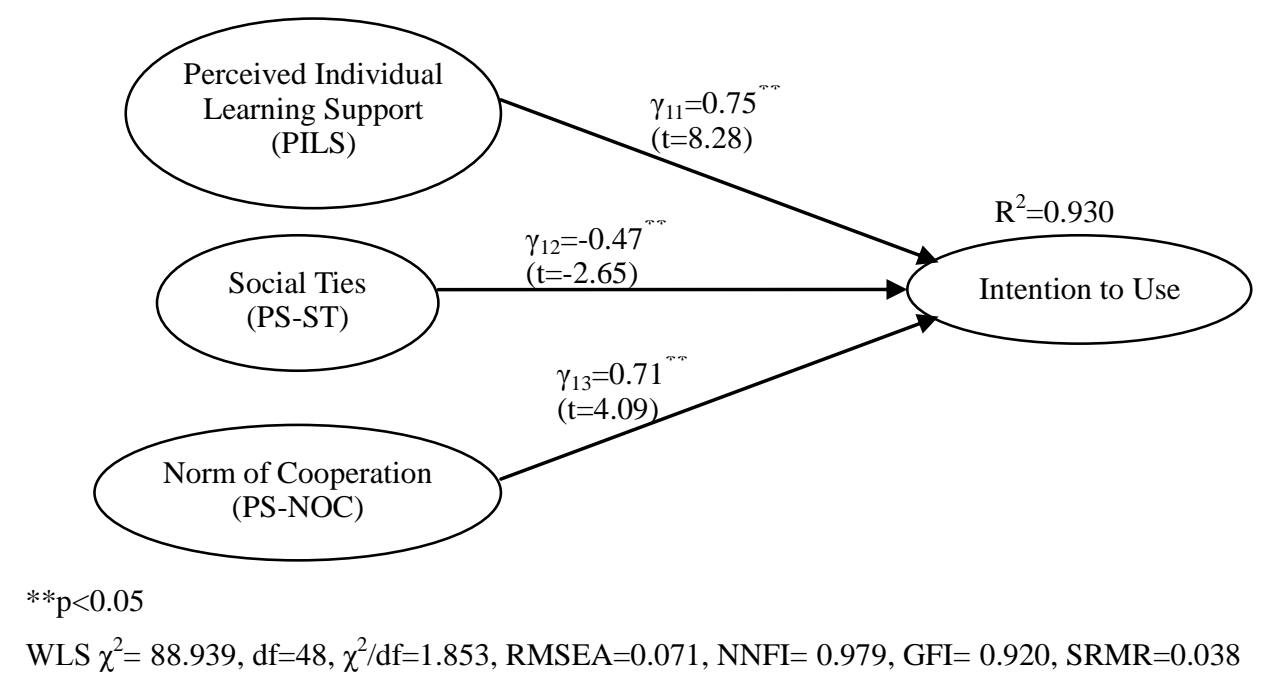

Figure 3. Structural model

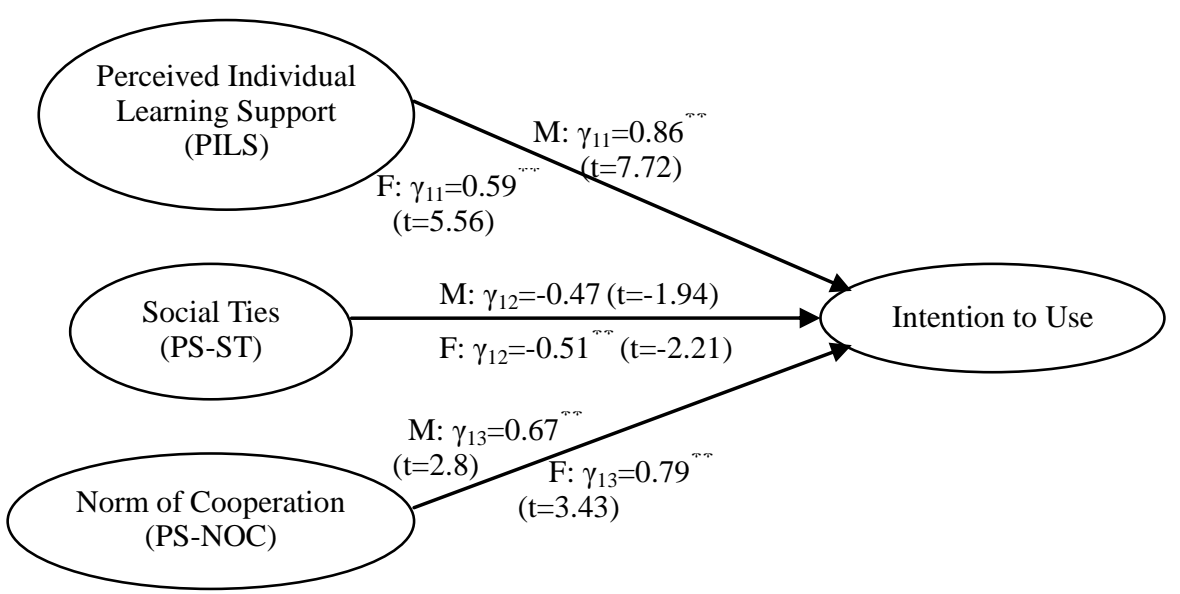

**p<0.05; M: The male group, F: The female group

Figure 4. Path coefficients for the male group and the female 


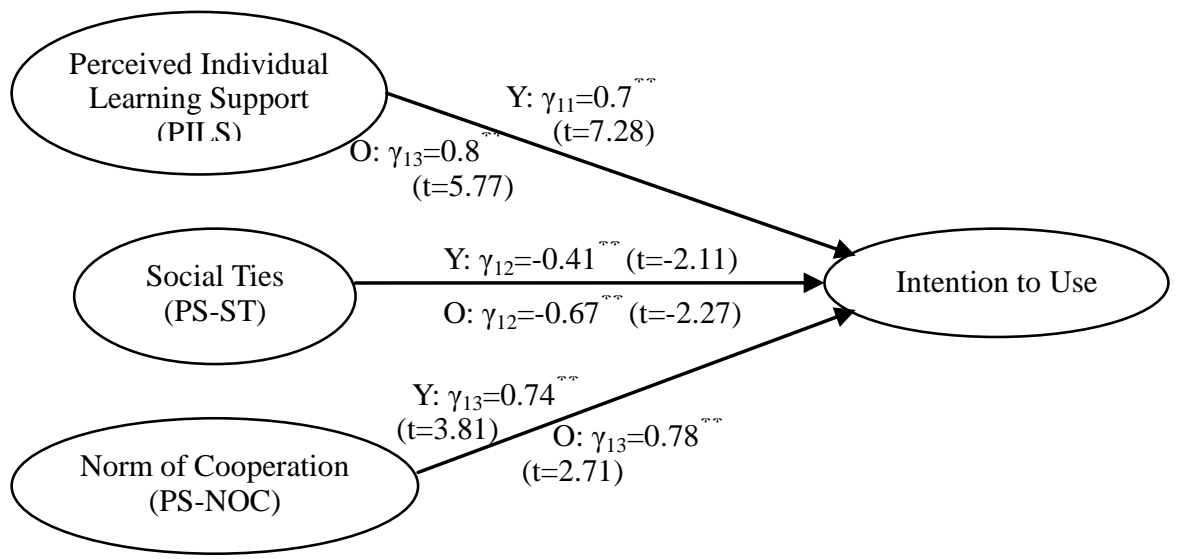

**p<0.05, Y: The younger group, O: The older group

Figure 5. Path coefficients for the younger group and the older group

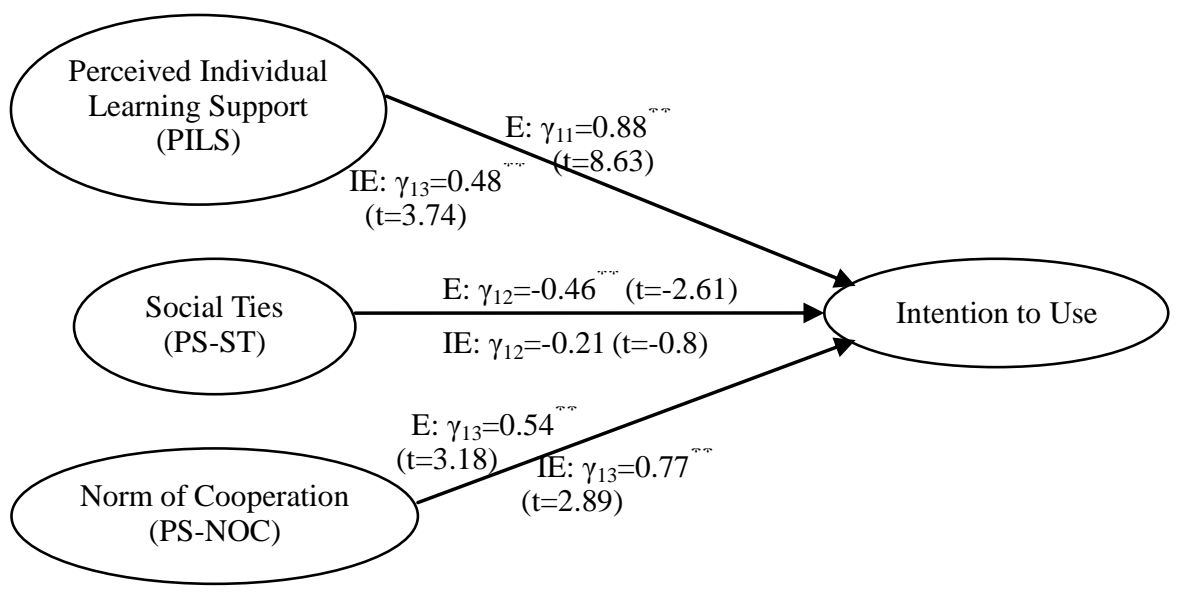

$* * \mathrm{p}<0.05, \mathrm{E}$ : The experienced group, IE: The inexperienced group

Figure 6. Path coefficients for the experienced group and the inexperienced group 


\section{$\underline{\text { Tables }}$}

Table 1. Conceptual validation

\begin{tabular}{|c|c|c|c|c|c|c|}
\hline \multirow{2}{*}{ Target construct } & \multicolumn{5}{|c|}{ Actual construct } & \multirow{2}{*}{ Inter-judge agreement } \\
\hline & PILS & PS-ST & PS-NOC & ITU & Other & \\
\hline \multicolumn{7}{|l|}{ PILS } \\
\hline Q1* & 12 & & & & & 1.00 \\
\hline $\mathrm{Q} 2 *$ & 10 & & & 2 & & 0.83 \\
\hline Q3* & 10 & 2 & & & & 0.83 \\
\hline Q4* & 10 & & & 2 & & 0.83 \\
\hline Q5 & 2 & & & 9 & 1 & 0.17 \\
\hline Q6* & 10 & & 1 & & 1 & 0.83 \\
\hline Q7* & 10 & 1 & & & 1 & 0.83 \\
\hline Q8 & 9 & & & 3 & & 0.75 \\
\hline \multicolumn{7}{|l|}{ PS-ST } \\
\hline Q1 & 5 & 6 & 1 & & & 0.50 \\
\hline $\mathrm{Q} 2 *$ & & 12 & & & & 1.00 \\
\hline $\mathrm{Q} 3 *^{\mathrm{a}}$ & & 9 & 4 & & & 0.75 \\
\hline $\mathrm{Q} 4^{\mathrm{a}}$ & & 5 & 8 & & & 0.42 \\
\hline $\mathrm{Q} 5^{\mathrm{a}}$ & & 6 & 7 & & & 0.50 \\
\hline Q6* & & 10 & 1 & & 1 & 0.83 \\
\hline \multicolumn{7}{|l|}{ PS-NOC } \\
\hline Q1* & & & 11 & & 1 & 0.92 \\
\hline $\mathrm{Q} 2 *$ & & 3 & 9 & & & 0.75 \\
\hline Q3* & & 1 & 11 & & & 0.92 \\
\hline \multicolumn{7}{|l|}{ ITU } \\
\hline $\mathrm{Q} 1 *$ & 1 & & & 11 & & 0.92 \\
\hline $\mathrm{Q} 2 *$ & 1 & 1 & 1 & 7 & 2 & 0.58 \\
\hline $\mathrm{Q} 3 *$ & & & & 12 & & 1.00 \\
\hline
\end{tabular}

${ }^{\mathrm{a}}$ One subject made multi-choice feedbacks on this item.

* Items preserved as indictors. 
Table 2. Demographics of sample respondents

\begin{tabular}{|c|c|c|}
\hline & Frequency & Percentage \\
\hline \multicolumn{3}{|l|}{ Gender } \\
\hline Male & 98 & $56.98 \%$ \\
\hline Female & 74 & $43.02 \%$ \\
\hline \multicolumn{3}{|l|}{ Age } \\
\hline $18-25$ & 30 & $17.44 \%$ \\
\hline $26-35$ & 90 & $52.33 \%$ \\
\hline $36-45$ & 36 & $20.93 \%$ \\
\hline $46-55$ & 15 & $8.72 \%$ \\
\hline Over 55 years old & 1 & $0.58 \%$ \\
\hline \multicolumn{3}{|l|}{ Education* } \\
\hline High school & 10 & $5.85 \%$ \\
\hline College / Associate degree & 34 & $19.88 \%$ \\
\hline University / Bachelor degree & 80 & $46.78 \%$ \\
\hline Graduate school / Master degree & 47 & $27.49 \%$ \\
\hline \multicolumn{3}{|l|}{ Work experience } \\
\hline $0-3$ years & 39 & $22.67 \%$ \\
\hline 3-6 years & 42 & $24.42 \%$ \\
\hline $6-9$ years & 16 & $9.30 \%$ \\
\hline $9-12$ years & 28 & $16.28 \%$ \\
\hline over 12 years & 47 & $27.33 \%$ \\
\hline \multicolumn{3}{|c|}{ Prior experience using online training systems } \\
\hline Yes & 115 & $66.86 \%$ \\
\hline No & 57 & $33.14 \%$ \\
\hline
\end{tabular}

* One case responds with missing data on educational background.

Table 3. Measurement model fit statistics

\begin{tabular}{|c|c|c|c|c|c|c|c|c|c|c|}
\hline Model & $\operatorname{WLS} \chi^{2}$ & $\mathrm{df}$ & $\chi^{2} / \mathrm{df}$ & $\mathrm{P}$ & RMSEA & $90 \% \mathrm{CI}$ & NNFI & CFI & GFI & SRMR \\
\hline Recommended value & & & $<2.0^{\mathrm{a}}$ & & $<0.10^{b}$ & & $>0.90^{\mathrm{c}}$ & $>0.90^{\mathrm{d}}$ & $>0.80^{\mathrm{e}}$ & $<0.05^{\mathrm{c}}$ \\
\hline Initial & 206.998 & 84 & 2.464 & 0.000 & 0.092 & $0.076 ; 0.108$ & 0.970 & 0.976 & 0.862 & 0.048 \\
\hline Revised & 88.939 & 48 & 1.853 & 0.000 & 0.071 & $0.047 ; 0.093$ & 0.979 & 0.985 & 0.920 & 0.038 \\
\hline
\end{tabular}

${ }^{\mathrm{a}}$ Carmines \& McIver (1981); ${ }^{\mathrm{b} B r o w n e} \&$ Cudeck. (1993); ${ }^{\mathrm{c}} \mathrm{Hu} \&$ Bentler (1999); ${ }^{\mathrm{d}}$ Bentler (1988);

${ }^{\mathrm{e}}$ Etezadi-Amolo \& Farhoomand (1996)

WLS $\chi^{2}$ : Normal Theory Weighted Least Squares Chi-Square; RMSEA: Root Mean Square Error of Approximation; 90\% CI: 90 Percent Confidence Interval for RMSEA; NNFI: Non-Normed Fit Index; CFI: Comparative Fit Index; GFI: Goodness of Fit; SRMR: Standardized Root Mean Square Residual 
Table 4. Reliability and convergent validity

\begin{tabular}{|c|c|c|c|c|c|c|c|}
\hline & $\lambda_{\mathrm{i}}$ & t-value & $\delta$ & t-value & Cronbach's $\alpha$ & $\mathrm{CR}$ & AVE \\
\hline \multicolumn{5}{|c|}{ Perceived Individual Learning Support } & 0.849 & 0.853 & 0.660 \\
\hline PILS1 & 0.777 & 11.639 & 0.397 & 7.593 & & & \\
\hline PILS2 & 0.844 & 13.150 & 0.288 & 6.507 & & & \\
\hline PILS3 & 0.816 & 12.516 & 0.334 & 7.051 & & & \\
\hline \multicolumn{5}{|c|}{ Perceived support for enhancing Social Ties } & 0.810 & 0.812 & 0.591 \\
\hline PS-ST1 & 0.773 & 11.315 & 0.403 & 7.090 & & & \\
\hline PS-ST2 & 0.789 & 11.661 & 0.377 & 6.823 & & & \\
\hline PS-ST3 & 0.743 & 10.719 & 0.448 & 7.469 & & & \\
\hline \multicolumn{5}{|c|}{ Perceived support for promoting a Norm Of Cooperation } & 0.866 & 0.870 & 0.692 \\
\hline PS-NOC1 & 0.875 & 14.064 & 0.235 & 6.177 & & & \\
\hline PS-NOC2 & 0.855 & 13.557 & 0.270 & 6.711 & & & \\
\hline PS-NOC3 & 0.762 & 11.412 & 0.420 & 7.990 & & & \\
\hline \multicolumn{5}{|l|}{ Intention To Use } & 0.885 & 0.886 & 0.722 \\
\hline ITU1 & 0.858 & 13.727 & 0.264 & 6.941 & & & \\
\hline ITU2 & 0.840 & 13.270 & 0.295 & 7.285 & & & \\
\hline ITU3 & 0.851 & 13.538 & 0.276 & 7.093 & & & \\
\hline
\end{tabular}

Table 5. Discriminant validity

\begin{tabular}{llrrr}
\hline \multicolumn{4}{c}{ PILS } & \multicolumn{2}{l}{ PS-ST } & \multicolumn{2}{l}{ PS-NOC } \\
\hline \multirow{2}{*}{ PS-ST } & avgAVE & 0.625 & & \\
\cline { 2 - 5 } & $\mathrm{r}\left(\mathrm{r}^{2}\right)$ & $0.433(0.187)$ & & \\
\hline \multirow{2}{*}{ PS-NOC } & avgAVE & 0.676 & 0.641 & \\
\cline { 2 - 5 } & $\mathrm{r}\left(\mathrm{r}^{2}\right)$ & $0.477(0.228)$ & $0.673(0.453)$ & 0.707 \\
\hline \multirow{2}{*}{ ITU } & avgAVE & 0.691 & 0.656 & $0.626(0.392)$ \\
\cline { 2 - 5 } & $\mathrm{r}\left(\mathrm{r}^{2}\right)$ & $0.748(0.560)$ & $0.459(0.211)$ & \\
\hline
\end{tabular}

Table 6. Measurement equivalence across the male group and the female group

\begin{tabular}{|c|c|c|c|c|c|c|c|c|}
\hline Model & WLS $\chi^{2}$ & $\mathrm{df}$ & $\chi^{2} / \mathrm{df}$ & RMSEA & $90 \% \mathrm{CI}$ & NNFI & CFI & GFI \\
\hline \multicolumn{9}{|l|}{ Stage 1} \\
\hline Entire & $88.939(\mathrm{p}=0.000)$ & 48 & 1.853 & 0.071 & $0.047 ; 0.093$ & 0.979 & 0.985 & 0.920 \\
\hline Male & $84.359(\mathrm{p}=0.001)$ & 48 & 1.757 & 0.088 & $0.056 ; 0.119$ & 0.972 & 0.980 & 0.846 \\
\hline Female & 79.907(p=0.003) & 48 & 1.665 & 0.095 & $0.056 ; 0.131$ & 0.924 & 0.945 & 0.873 \\
\hline \multicolumn{9}{|l|}{ Stage 2} \\
\hline Base model & $164.541(\mathrm{p}=0.000)$ & 96 & 1.714 & 0.092 & $0.067 ; 0.115$ & 0.961 & 0.972 & 0.845 \\
\hline$\lambda$ constrained & $\begin{array}{r}172.828(\mathrm{p}=0.000) \\
\triangle \chi^{2}=8.287^{\mathrm{ns}}\end{array}$ & $\begin{array}{r}104 \\
\triangle \mathrm{df}=8\end{array}$ & 1.662 & 0.088 & $0.064 ; 0.111$ & 0.964 & 0.972 & 0.839 \\
\hline
\end{tabular}

\footnotetext{
${ }^{\mathrm{ns}}$ Not significant.
} 
Table 7 Multi-group comparison of path coefficients for male and female

\begin{tabular}{cccccccccc}
\hline \multicolumn{1}{c}{ Model $^{2}$} & $d f$ & $\Delta \chi^{2}$ & $\Delta d f$ & RMSEA & 90 Percent CI & NNFI & CFI & GFI \\
\hline Base model $^{\text {a }}$ & $190.965(p=0.000)$ & 110 & & & 0.093 & $0.07051 ; 0.1148$ & 0.960 & 0.966 & 0.820 \\
$\gamma_{11}$ constrained $^{\mathrm{b}}$ & $195.179(p=0.000)$ & 111 & $4.214^{* *}$ & 1 & 0.094 & $0.07219 ; 0.1160$ & 0.959 & 0.966 & 0.815 \\
$\gamma_{12}$ constrained $^{\mathrm{b}}$ & $190.917(p=0.000)$ & 111 & $-0.048^{\mathrm{ns}, \mathrm{c}}$ & 1 & 0.092 & $0.06946 ; 0.1138$ & 0.960 & 0.967 & 0.820 \\
$\gamma_{13}$ constrained $^{\mathrm{b}}$ & $190.945(p=0.000)$ & 111 & $-0.020^{\mathrm{ns}, \mathrm{c}}$ & 1 & 0.092 & $0.06947 ; 0.1138$ & 0.960 & 0.967 & 0.820 \\
\hline
\end{tabular}

${ }^{\mathrm{a}}$ All paths for the two groups are allowed to be freely estimated.

${ }^{\mathrm{b}}$ The path specified is constrained to be equal across the two groups.

${ }^{\mathrm{c}}$ The value of $\Delta \chi^{2}$ is supposed to be greater than 0 . The two negative values are probably due to the sampling error since the values are not significant.

${ }^{\mathrm{ns}}$ Not significant.

${ }^{* *} p<0.05$.

Table 8. Measurement equivalence across the younger group and the older group

\begin{tabular}{lrrrrrrrr}
\hline \multicolumn{1}{c}{ Model } & WLS $\chi^{2}$ & DF & $\chi^{2} / \mathrm{df}$ & RMSEA & $90 \%$ CI & NNFI & CFI & GFI \\
\hline \multicolumn{1}{c}{ Stage 1 } & & & & & & & & \\
Entire & $88.939(\mathrm{p}=0.000)$ & 48 & 1.853 & 0.071 & $0.047 ; 0.093$ & 0.979 & 0.985 & 0.920 \\
Young & $71.757(\mathrm{p}=0.015)$ & 48 & 1.495 & 0.064 & $0.029 ; 0.094$ & 0.984 & 0.988 & 0.909 \\
Old & $72.796(\mathrm{p}=0.012)$ & 48 & 1.517 & 0.101 & $0.048 ; 0.146$ & 0.927 & 0.947 & 0.808 \\
\hline Stage 2 & & & & & & & \\
Base model & $144.553(\mathrm{p}=0.001)$ & 96 & 1.506 & 0.077 & $0.050 ; 0.102$ & 0.970 & 0.978 & 0.808 \\
$\lambda$ constrained & $\begin{array}{r}154.138(\mathrm{p}=0.001) \\
\triangle \chi^{2}=9.5848\end{array}$ & 104 & 1.482 & 0.075 & $0.049 ; 0.099$ & 0.971 & 0.977 & 0.795 \\
\hline
\end{tabular}

\footnotetext{
${ }^{\mathrm{ns}}$ Not significant.
}

Table 9. Multi-group comparison of path coefficients for younger people and older people

\begin{tabular}{cccccccccc}
\hline \multicolumn{1}{c}{ Model } & $\chi^{2}$ & $d f$ & $\Delta \chi^{2}$ & $\Delta d f$ & RMSEA & 90 Percent CI & NNFI & CFI & GFI \\
\hline Base model & $182.406(\mathrm{p}=0.00)$ & 122 & & & 0.076 & $0.052 ; 0.099$ & 0.967 & 0.969 & 0.725 \\
$\gamma_{11}$ constrained & $183.049(\mathrm{p}=0.00)$ & 123 & $0.643^{\mathrm{ns}}$ & 1 & 0.076 & $0.051 ; 0.098$ & 0.967 & 0.969 & 0.724 \\
$\gamma_{12}$ constrained & $183.286(\mathrm{p}=0.00)$ & 123 & $0.879^{\mathrm{ns}}$ & 1 & 0.076 & $0.052 ; 0.098$ & 0.967 & 0.969 & 0.723 \\
$\gamma_{13}$ constrained & $182.421(\mathrm{p}=0.00)$ & 123 & $0.015^{\mathrm{ns}}$ & 1 & 0.075 & $0.051 ; 0.098$ & 0.967 & 0.969 & 0.723 \\
\hline
\end{tabular}

${ }^{a}$ All paths for the two groups are allowed to be freely estimated.

${ }^{\mathrm{b}}$ The path specified is constrained to be equal across the two groups.

${ }^{\mathrm{ns}}$ Not significant.

${ }^{* *} p<0.05$. 
Table 10. Measurement equivalence across the experienced group and the inexperienced group

\begin{tabular}{|c|c|c|c|c|c|c|c|c|}
\hline Model & WLS $\chi^{2}$ & DF & $\chi^{2} / \mathrm{df}$ & RMSEA & $90 \% \mathrm{CI}$ & NNFI & $\mathrm{CFI}$ & GFI \\
\hline \multicolumn{9}{|l|}{ Stage 1} \\
\hline Entire & $88.939(\mathrm{p}=0.000)$ & 48 & 1.853 & 0.071 & $0.047 ; 0.093$ & 0.979 & 0.985 & 0.920 \\
\hline Yes & $85.519(\mathrm{p}=0.001)$ & 48 & 1.782 & 0.083 & $0.053 ; 0.111$ & 0.967 & 0.976 & 0.889 \\
\hline No & $61.034(\mathrm{p}=0.098)$ & 48 & 1.272 & 0.070 & $0.00 ; 0.118$ & 0.976 & 0.982 & 0.846 \\
\hline \multicolumn{9}{|l|}{ Stage 2} \\
\hline Base model & $146.553(\mathrm{p}=0.098)$ & 96 & 1.527 & 0.079 & $0.052 ; 0.103$ & 0.970 & 0.978 & 0.846 \\
\hline$\lambda$ constrained & $\begin{array}{r}147.732(\mathrm{p}=0.003) \\
\triangle \chi^{2}=1.179^{\mathrm{ns}}\end{array}$ & $\begin{array}{r}104 \\
\triangle \mathrm{df}=8 \\
\end{array}$ & 1.420 & 0.070 & $0.042 ; 0.095$ & 0.974 & 0.980 & 0.844 \\
\hline
\end{tabular}

${ }^{\mathrm{ns}}$ Not significant.

Table 11. Multi-group comparison of path coefficients for the experienced group and the inexperienced group

\begin{tabular}{cccccccccc}
\hline \multicolumn{1}{c}{ Model $^{2}$} & $\chi^{2}$ & $d f$ & $\Delta \chi^{2}$ & $\Delta d f$ & RMSEA & 90 Percent CI & NNFI & CFI & GFI \\
\hline Base model $^{\text {a }}$ & $200.492(\mathrm{p}=0.000)$ & 122 & & & 0.087 & $0.065 ; 0.108$ & 0.971 & 0.973 & 0.792 \\
$\gamma_{11}$ constrained $^{\mathrm{b}}$ & $206.148(\mathrm{p}=0.000)$ & 123 & $5.656^{* *}$ & 1 & 0.089 & $0.067 ; 0.110$ & 0.968 & 0.970 & 0.786 \\
$\gamma_{12}$ constrained $^{\mathrm{b}}$ & $202.216(\mathrm{p}=0.000)$ & 123 & $1.724^{\mathrm{ns}}$ & 1 & 0.087 & $0.065 ; 0.108$ & 0.971 & 0.973 & 0.791 \\
$\gamma_{13}$ constrained $^{\mathrm{b}}$ & $200.734(\mathrm{p}=0.000)$ & 123 & $0.242^{\mathrm{ns}}$ & 1 & 0.086 & $0.064 ; 0.107$ & 0.971 & 0.973 & 0.792 \\
\hline
\end{tabular}

${ }^{\mathrm{a}}$ All paths for the two groups were allowed to be freely estimated.

${ }^{\mathrm{b}}$ The path specified was constrained to be equal across the two groups.

${ }^{\mathrm{ns}}$ Not significant.

${ }^{* * *} p<0.05$. 
Table 12 . Summary of hypotheses testing results

\begin{tabular}{llll} 
& \multicolumn{1}{c}{ Relationship } & \multicolumn{1}{c}{ Hypotheses } & \multicolumn{1}{c}{ Testing result } \\
\hline Main effect & & & Supported \\
H1a & PILS $\rightarrow$ ITU & Positive & Not supported, negative \\
H2a & PS-ST $\rightarrow$ ITU & Positive & Supported \\
H3a & PS-NOC $\rightarrow$ ITU & Positive & \\
\hline Gender difference & & & Supported \\
H1b & PILS $\rightarrow$ ITU & Men>Women & Not supported \\
H2b & PS-ST $\rightarrow$ ITU & Men>Women & Not supported \\
H3b & PS-NOC $\rightarrow$ ITU & Men>Women & \\
- Age difference & & & Not supported \\
H1c & PILS $\rightarrow$ ITU & Younger>Older & Not supported \\
H2c & PS-ST $\rightarrow$ ITU & Younger $>$ Older & Not supported \\
H3c & PS-NOC $\rightarrow$ ITU & Younger>Older & \\
\hline Prior experience difference & PILS $\rightarrow$ ITU & Experienced $>$ Inexperienced & Supported \\
H1d & PS-ST $\rightarrow$ ITU & Experienced $>$ Inexperienced & Not supported \\
H2d & PS-NOC $\rightarrow$ ITU & Experienced $>$ Inexperienced & Not supported \\
H3d & & & \\
\hline & & & \\
\hline
\end{tabular}


Appendix I: Survey instrument

Perceived Individual Learning Support (PILS)

1. The system would be helpful for me to construct knowledge in my work context. (Kirkpatrick \& Kirkpatrick, 2006)

2. Using this system would enhance effectiveness in my work-related learning. (Davis, 1989)

3. This system would be helpful for me to identify my knowledge gaps or learning needs. (Kirkpatrick \& Kirkpatrick, 2006)

Perceived support for enhancing Social Ties (PS-ST)

1. In my perception, this system can promote interaction between my colleagues. (Chiu, Hsu \& Wang, 2006)

2. This system would be helpful for broadening connections among employees in my company. (van der Gaag, 2005)

3. In my perception, this system would be helpful for closer relationships between my colleagues. (Chiu, Hsu \& Wang, 2006)

Perceived support for promoting a Norm Of Cooperation (PS-NOC)

1. This learning platform would be helpful for formation of a workplace climate of cooperation in work-related learning. （Kankanhalli, Tan \& Wei, 2005)

2. This learning platform would be helpful for formation of a workplace climate of peer mentoring and coaching. (Self-developed based on Noe, Wilk, Mullen, \& Wanek, 1997)

3. This learning platform would be helpful for formation of a workplace climate of teamwork. (Kankanhalli, Tan \& Wei, 2005)

Intention To Use (ITU)

1. Given that I had access to the system, I predict that I would use it. (Venkatesh \& Davis, 2000)

2. If possible, I would recommend this learning platform to other teammates. (Kirkpatrick \& Kirkpatrick, 2006)

3. Assuming I have access to the system, I intend to use it. (Venkatesh \& Davis, 2000) 